\title{
STATE OF CALIFORNIA
}

ENERGY RESOURCES CONSERVATION AND

\section{DEVELOPMENT COMMISSION}

\section{MASTER}

POWER PLANT PERFORMANCE ANALYSIS

\author{
AND \\ GUIDELINES STUDY \\ APPENDIX II \\ $D E-F C O 1-77 R A O 8137$
}

BY

SYSTEM DEVELOPMENT CORPORATION

SANTA MONICA, CALIFORNIA 


\section{DISCLAIMER}

This report was prepared as an account of work sponsored by an agency of the United States Government. Neither the United States Government nor any agency Thereof, nor any of their employees, makes any warranty, express or implied, or assumes any legal liability or responsibility for the accuracy, completeness, or usefulness of any information, apparatus, product, or process disclosed, or represents that its use would not infringe privately owned rights. Reference herein to any specific commercial product, process, or service by trade name, trademark, manufacturer, or otherwise does not necessarily constitute or imply its endorsement, recommendation, or favoring by the United States Government or any agency thereof. The views and opinions of authors expressed herein do not necessarily state or reflect those of the United States Government or any agency thereof. 


\section{DISCLAIMER}

Portions of this document may be illegible in electronic image products. Images are produced from the best available original document. 
Mechanics

2SOO COLORADO AVENUE - SANTA MONICA, CALIFORNIA 90406 Mesearch

a division of

System Development Corporation

.

POWER PLANT

PERFORMANCE ANALYSIS

AND

GUIDELINES STUDY

APPENDIX II

RELIABILITY AND EFFICIENCY

INDICES

TPE 16.5-A.II

June 1978

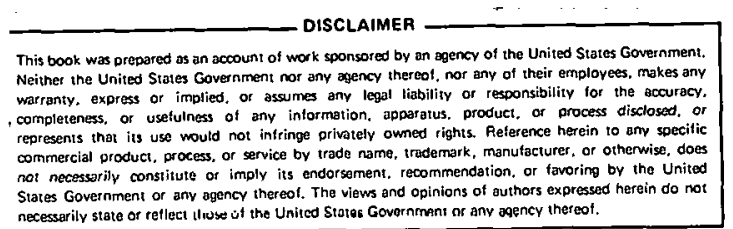

For Comment and/or Clarification Contact:

Richard W. Keller

Ajay Bhatla

Morton J. Smith 
Four indices of power plant performance have been identified for use by the CERCDC in the technical evaluation of cost-effective levels of reliability and efficiency of future power plants, to be sited in the state of ralifnrnia. The selected indices are Capacity Factor, Operating Availability, Equivalent Availability and Heat Rate. The write-up on each index includes a discussion on the Index Definition, Historical Data Avallability/Sources and Recommendations for Application by the Commission. 


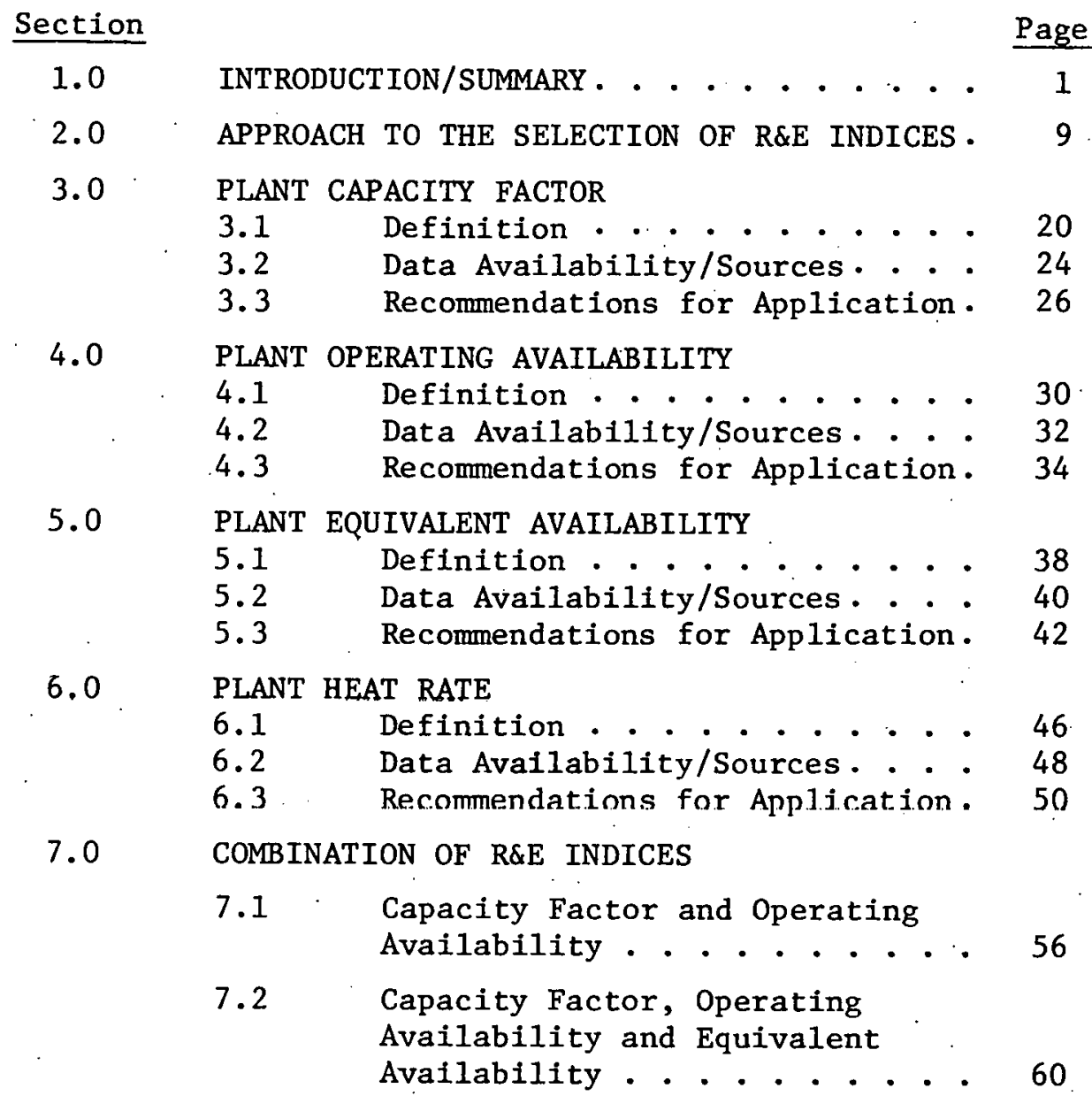




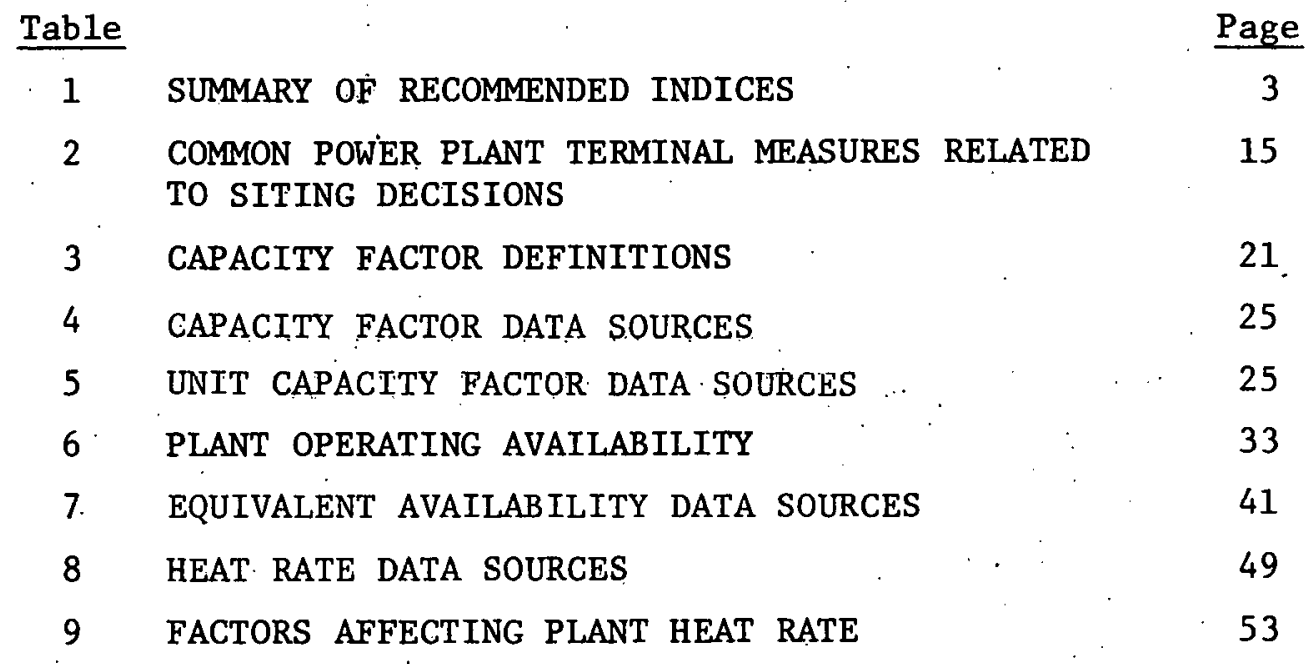

\section{LIST OF FIGURES}

\begin{tabular}{|c|c|c|}
\hline Figures & & $\underline{\text { Page }}$ \\
\hline 1 & EXTERNAI INFLUENCES ON PLANT PERFORMANCE & 11 \\
\hline 2 & INFLUENCES INTERNAL TO A PLANT & 13 \\
\hline 3 & METHOD OF ACCOUNTING FOR CAPACITY FACTOR LOSS & 27 \\
\hline 4 & OPERATING AVAILABILITY DEFINITION & 31 \\
\hline 5 & OPERATING AVAILABILITY AND OUTAGE RATES & 35 \\
\hline 6 & EQUIVALENT AVAILABILITY DEFINITION & 39 \\
\hline 7 & ETFECT OF OUTAGES ON EQUIVALENT AVAILABILITY & 43 \\
\hline 8 & DEFINITION OF HEAT RATE & 47 \\
\hline 9 & $\begin{array}{l}\text { RELATIONSHIP BETWEEN HEAT RAIE AND GENERATOR } \\
\text { OUTPUT }\end{array}$ & 51 \\
\hline 10 & $\begin{array}{l}\text { CAPACITY FACTOR AND OPERATING AVAILABILITY } \\
\text { RELATIONSHIPS }\end{array}$ & 57 \\
\hline 11 & $\begin{array}{l}\text { CAPACITY FACTOR AND OPERATING AVAILABILITY } \\
\text { BELATIONSHIPS BASED UPON RESERVE SHUTDOWN TIME }\end{array}$ & 59 \\
\hline 12 & $\begin{array}{l}\text { CAPACITY FACTOR, OPERATING AVAILABILITY AND } \\
\text { EQUIVALENT AVAILABILITY }\end{array}$ & 61 \\
\hline
\end{tabular}


SECTION 1.0

INTRODUCTION/SUMMARY 
A review and evaluation of terms used within the electric power industry to define and assess various aspects of reliability and efficiency of power plants, has led to the identification of four indices which are most useful for evaluating AFC submittals. These indices are (1) Capacity Factor, (2) Operating or Unit Availability, (3) Equivalent Availability, and (4) Heat Rate. These terms are not new and they are commonly used by utility personnel, regulators and investigators of historical power plant productivity problems. It is recommended that these four indicies become the focus of discussions concerning costeffective levels of reliability and efficiency for proposed power plants to be sited in the state of California.

These indices have been selected because they can be used individually and in combination to establish the cost-effectiveness of addition of specific sizes and types of power plants. Each index relates directly to one or more critical elements in the siting decision process; for example, projection of capacity factors will enable the Commission to ascertain if the size of the proposed power plant is consistent with future projections of electrical energy needed in California. Similarly, a projection of operating availability will enable the Commission to determine if the proposed power plant is capable of meeting its generation time requirements; a projection of equivalent availability will enable a determination if the proposed plant is capable of meeting its generation requirements; and a projection of heat rate will determine if the plant will operate within the monies allocated.

The recommended indices are considered to be appropriate for Commission leve1 decision making: additionally, evaluation of their constituent parts (e.g., reserve shutdown hours, full forced outages and full scheduled outages for operating availability) provides an effective means for addressing plant utilization, design, construction, operation, maintenance and alternate utility policies for assuring that proposed levels for these indices will be achieved cost-effectively.

\section{PLANT CAPACITY FACTOR}

Capacity factor is a measure of the amount of unit generation capability actually realized from an existing unit or proposed to be generated from a new unit. By 


\section{CAPACITY FACTOR}

ATTRIBUTES

- QUANTIFIES PRODUCTION UTILIZATION

- USEFUL FOR ESTABLISHING ENERGY PLANNED FOR DISTRIBUTION

- PROVIDES SYSTEMATIC ACCOUNTING METHOD OF POWER PRODUCTION

- useful in eVAluating cost-efFectIVENESS OF PROPOSED FACILITIES
LIMITATIONS

- INCONSISTENCY OF HISTORICAL DATA BASE

- SUBJect to load Demand and many OTHER INFLUENCES

\section{OPERATING AVAILABILITY \\ ATTRIBUTES \\ LIMITATIONS}

- ESTABGISHES PRODUCTION REQUIREMENT TTIME)

- INCONSISTENCY OF HISTORICAL DATA BASE

- bounds time aVAilable for full forced AND PLANNED OUTAGES

- eower leVel available upon DEMAND UNKNOWN

- PROVIDES METHOD FOR DETERMINING EFFECTIVENESS OF PROGRAMS TO CONTROL UNAVAILABILITY

- measure of reliability

\section{EQUIVALENT AVAILABILITY}

ATTRIBUTES

\section{LIMITATIONS}

- ESTABLISHES FULL POWER PRODUCTION CAPABILITY

- INCONSISTENCY OF HISTORICAL DATA BASE

- BOUNDS ITIME AVAILABLE FOR FULL AND PARTIAL OUTAGES

- PROVIDES METHOD FOR DETERMINING EFFECTIVENESS OF PROGRAMS TO CONTROL OUTAGES

- meAsURE OF RELIABILITY

\section{HEAT RATE}

ATTRIBUTES

LTIITATIONS

- MEASURE OF THERMODYNAMIC EFFICIENCY

- INCONSISTENCY OF HISTORICAL DATA

- INDICATOR OF COST-EFFECTIVENESS OF ALBASE

TERNATE FUEL TYPES AND PRODUCTION RATES

NOT UNIFORMLY RECORDED FOR IN-

- USEFul for evaluating loAding ORDER DIVIDUAL. UNITS

- MEASUREMENT ACCURACY 
itself, capacity factor provides little insight into plant reliability or efficiency. In the earliest stages of planning, capacity factor estimates need to be used for establishing the sizes and possible fuel mixes of future units to achieve a match between installed capacity and future energy supply requirements.

The Commission may use capacity factor estimates to determine if a unit has been properly sized, based upon independent assessments of future California energy requirements. The decision determining the cost-effectiveness of the proposed capacity addition requires two additional evaluations: (1) an assessment of the prevailing rate base and the revenue required to maintain the rate structure for all possible new generation additions (size and fuel types) which could conceivably meet the projected energy load profile, and (2) an assessment, for the final selected unit(s), of the deviation in this projected capacity factors from what might be considered normal (from historical data), for similar size, design, etc. The added "potential" cost of both' achieving the proposed capacity factor, requires an evaluation in terms of the impact of the deviations in capacity factor on the rate base and resultant revenue requirements. This assessment of the cost-effectiveness of the proposed capacity addition is dependent upon the capacity factor achieved by the new units, which is influenced by the loading scheme proposed by the utility and agreed to by the rommission.

Capacity factor data can be used by the Commission to evaluate the losses (decrease in power plant generation) due to outages and power reductions to identify the causes of lost capacity. The Capacity Accounting Method detailed in section 3.3 requires that the principal elements of lost productivity (capacity losses due to outages, economic dispatch restrictions, etc.) be identified. These elements need to be controlled if high capacity factors are to be achieved. Plant design, construction, operation, maintenance, utilization, etc. are some of the areas that require careful consideration for the identification of the causes of lost capacity leading to the control and reduction of historical capacity losṣes. 
The major limitation to using capacity factor as an index is the lack of a wellestablished, accurate data base for historical comparison of units. This is not to say that data does not exist, but rather, the data available do not adequately account for low capacity factors brought about by economic considerations (load following, spinning revenue, etc.), regulatory constraints (reduced power levels to reduce emmissions, emmission equipment testing, etc.), and other factors which have no bearing on the inherent reliability or efficiency of individual units and their component/equipment. An additional drawback to using capacity factor is the lack of a universally accepted definition of the actual generation capability of a power plant, a major element in its calculation.

\section{PLANT OPERATING AVAILABILITY}

A capacity factor projection establishes the magnitude of electrical power required from a plant, but it does not provide any estimate as to the time period during which the plant is required to generate power. Operating Availability is an index of production capacity readiness or preparedness i.e., is a measure of a power plant's ability to generate some power.

Operating Availability projections establish the period or percentage of time a proposed unit will be required to be available to meet some level of demand. Once the required operating availability over a time period is determined, the allowable unavailability of the unit, during the same time period, will also be determined. This unavailable time period for large units is usually reserved for planned annual maintenance and overhaul of major plant equipment; additionally, unplanned maintenance requirements (e.g., forced full outages due to equipment failure) are also included in this portion of the time period. Thus, when operating availability is fixed, unit shutdown time is also fixed.

Operating Availability provides a method for determining the effectiveness of programs to control plant unavailability. Historical data provides trends of change in total outage (full forced plus scheduled) time. Review of this outage data will allow the Cómmission to assure that forced outages will be minimized and that scheduled outage management and control will be conducted effectively to keep outage time within the planned unavailability time for new power p.lants. 
A limitation to the use of historical data on operating availability is the lack of precision in its recording: The reserve shutdown hours (hours a plant is out of service but available for operation), a major component of operating availability cannot be confirmed to have been regorously documented for all units. Also, Data on operating availability provides no information on the output power leve1 required of the unit during the period it is available to generate power.

\section{PLANT EQUIVALENT AVAILABILITY}

Capacity factor is a measure of the electric power required to be generated by a proposed plant. Information on the time period during which the required power is to be generated is not available from plant capacity factor data. Operating availability provides information on the time period during which some electric power s.an he generated hy a power plant. Caparity fartor and operating availability when specified together for a power plant and based upon the same time period, bound the periods of generation and non-generation (full outages), in addition to fixing the average useful energy level at which the plant needs:to operate to achieve its projected capacity factor. The difference between this average output energy level and the plant design electrical rating are reserve shutdowns/reductions and partial outages. Equivalent availability has been reviewed for use as an index by the Commission for alone it establishes the maximum generation capability of a plant and together with capacity factor and operating availability it provides the Commission with information on the partial outages (both forced and scheduled) that are anticipated. The control and reduction of partial outages can be under taken by the Commission if equivalent availability is used as an index.

Equivalent availability projections establish the maximum planned capability for meeting demand. The difference between equivalent, equivalent availability must factor is the spinning reserve requirements planned for the unit; when a unit is not planned to meet any reserve requriements, equivalent availability must be identically equal to capacity factor.

Equivalent Availability is perhaps the best measure of reliability in any of the national data banks, available today. It provides for accounting of all forms and types of power reductions at a unit. For this reason, the Commission may use equivalent availability projections as a method for reviewing unit design 
capability to achieve the proposed levels. Elements of redundancy and design reliability are two key aspects of unit design which ultimately impact EA.

The major limitation to using $\mathrm{EA}$ as an index is similar to the other indices: that is historical data may not precisely reflect past unit conditions.

\section{PLANT HEAT RATE}

Heat rate is the only measure of the thermodynamic efficiency available for power plants. Heat rate is one of the basic design parameters for a proposed unit and is a measure of the operating condition of an existing unit. Heat rale is directly dependent on the efficiency of all processes involved in the conversion of fuel energy into electrical power in a power plant. Heat rate is also dependent upon the level of plant power output at any specific instant of time. This is due to the relative inefficiencies of plant systems and equipment and the basic energy. conversion processes at different operating levels.

Heat rate data is not available on all units, on a individual unit basis, from national data banks (FPC etc.). Heat rate for a power generating installation, usually comprised of more than a single unit, is available in these national data banks. Although heat rate is not uniformly recorded for all units on an individual basis, it is usually tracked very closely, by each utility, during the life of a unit to determine the most cost-effective, incremental loading order of units. Units with a markedly lower heat rate are logical choices for base loaded generation while those with a markedly higher heat rate are generally used as peaking units only. In California, however, environmental conditions control unit dispatch and loading order. For example, in the Los Angeles Basin plants are subject to dispatch based. upon the atmospheric $\mathrm{NO}_{\mathrm{x}}$ levels and not unit heat rate. Heat rate can affectively be used as a primary index in defining the loading order and cost-effectiveness of different sizes and types of units, when regulatory restrictions do not require an alternate loading scheme.

As indices, capacity factor, operating availability, equivalent availability and heat rate provide a comprehensive description of the cost-effectiveness of reliability and efficiency proposed for a power plant. Each index establishes a significant aspect of the power plant which the Commission must consider in 
reaching a siting decision. For example, capacity factor is not only a measure of the generation capacity required, but when used in conjunction with operating availability, it establishes the total amount of time in an operating period available for all types of full outages. When these two indices are fixed, the magnitude (hours and capacity lost) of generation period of zero output are bounded. This provides the commission with insight into design and maintenance requirements which assure that capacity losses due to all types of full outages can be controlled. When equivalent availability is included in the evaluation; the time periods and average capacity losses due to partial outages (scheduled and forced) are also controlled. When heat rate is included in the evaluation, the most costeffective and fuel-efficient design can be determined for the intended application. 
SECTION 2.0

APPROACH TO THE SELECTION OF R\&E INDICES 
The approach to determining indices of power plant reliability and efficiency that would be of greatest use to the Commission, in the evaluation of utility AFC submittals is based upon two evaluations, namely, 1) and evaluation of the indicators presently used to assess the performance of power plants with special emphasis on plant reliability and efficiency, and 2) identification of indices of reliability and efficiency that could be used to satisfy siting decision information requirements for AFC approval, by the Comnission.

Indicators presently used by the industry to assess the performance of power plants were identified by a review of the available data systems and a survey of the reference literature. The data systems reviewed, FiFI and NRC, are established data collection systems, and are considered as reputable data sources of historical performance of power plants in the U.S. Acceptance of the data sources was validated by confirming their use by utility organizations, regulatory agencies and well known authors of the literature surveyed.

Each appropriate data element, in these data systems, was evaluated to assess its usefullness in defining the performance (reliability, efficiency and cost) of a power plant. The literature was surveyed to identify data elements that have historically been used, either individually or in combination, to define the reliability/efficiency/cost. of a power plant.

To evaluate the usefulness of a data element, for assessing the ongoing performance of a power plant, it was necessary to establish criteria that reflected the many facets of operating a power plant in a utility system. These facets include the demand made on a plant from sources external to it and those that affect its operation from within. Criteria were defined by charting a broad range of generic, significant influences affecting the optimum functioning of a power plant. Figures 1 and 2 chart the influences on plant operation due to elements external and internal, respectively, to the plant.

As depicted in figure 1, the total cost to the consumer is based upon the cost to the utility of doing business; to provide electrical service and meet socio- 


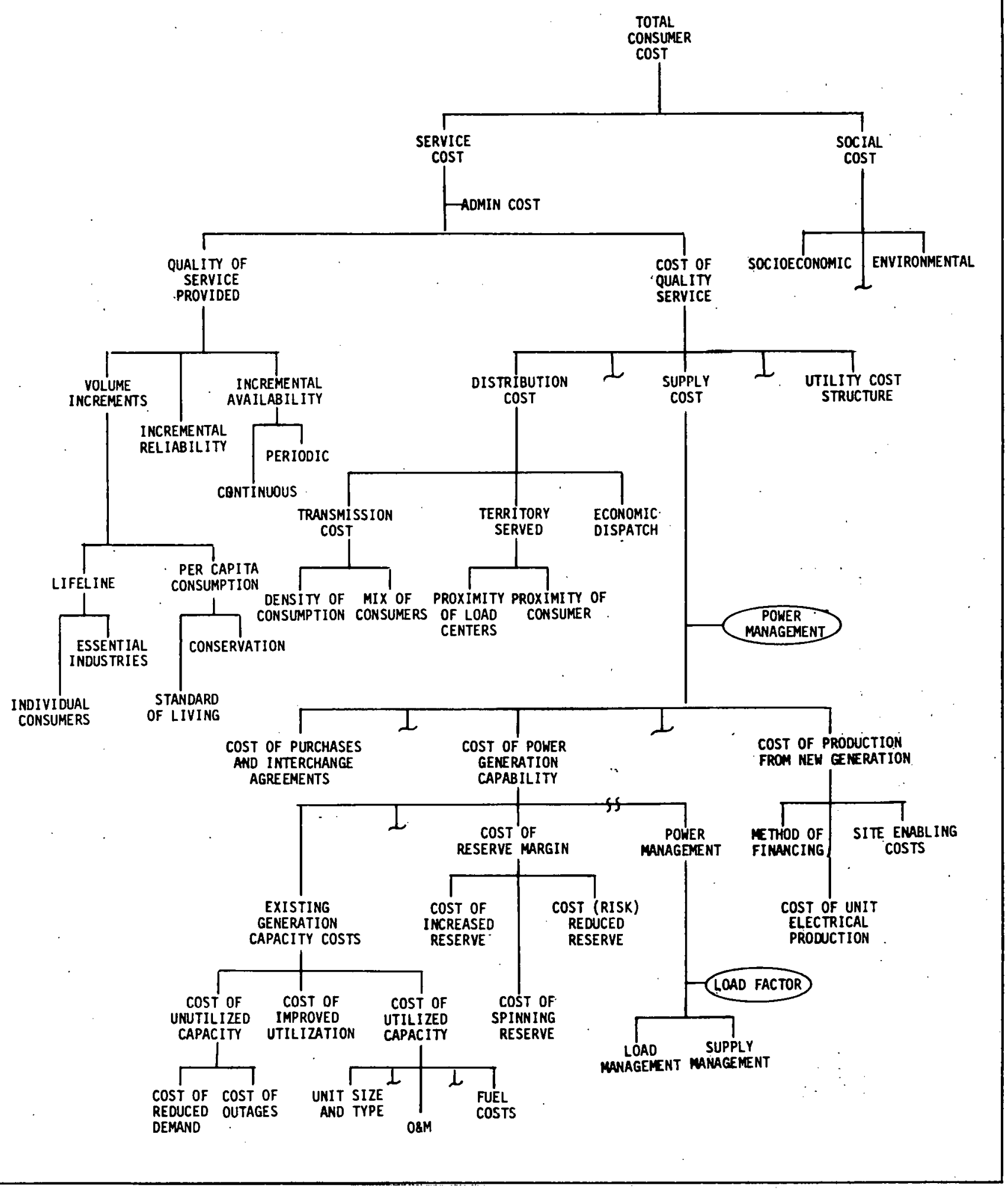

Figure 1: External Influences on Plant Performance 
economic and environmental costs. The social costs incurred by the consumer (directly or indirectly) may be disproportionate when compared with the cost of receiving additional electrical energy. No attempt has been made in this study to account for this socia-economic cost or compare it with the cost of providing electrical energy (service cost).

The service cost to the consumer is strongly dependent on what the consumer demands in the way of service. The utilities are required to provide highly reliable, continuous electrical power in the quantities desired at any time by the consumer. Additionally, the economic environment in which a utility is required to operate has changed drastically. Since 1973 and the oil embargo; the cost of providing society with high quality service has increased dramatically. Although the consumer, and others who attempt to measure or evaluate utility performance, rely heavily on a unit of measure by which electrical power is purchásed (i.e. mills/Kwh), considerations of cost-effectiveness must necessarily entall additional consideration for the high quality of electrical service. As an indicator, this parameter of cost is not addressed directly in the study; it is however considered indirectly in terms of the continuity and level of service required from the new generating capacity.

As illustrated by figure 1, the cost of providing, a specific level of quality service is not totally within the control of the utility. Many variables and characteristics of a utility have been used at this level, by many researchers, in an attempt to evaluate cost-effectiveness. Admittedly, many of these variables, as shown in the figure, need to be thoroughly evaluated in the siting process as they do impact the cost of production from new generation, which is shown to be a consideration, which is ultimately the objective of this study.

Figure 2, illustrates the relationship of power plant performance indicators internal to the power plant to the total cost of production from the new generation. The interrelationship of each indicator as shown by this figure was purposely structured to present a maximum of terms currently used by the 


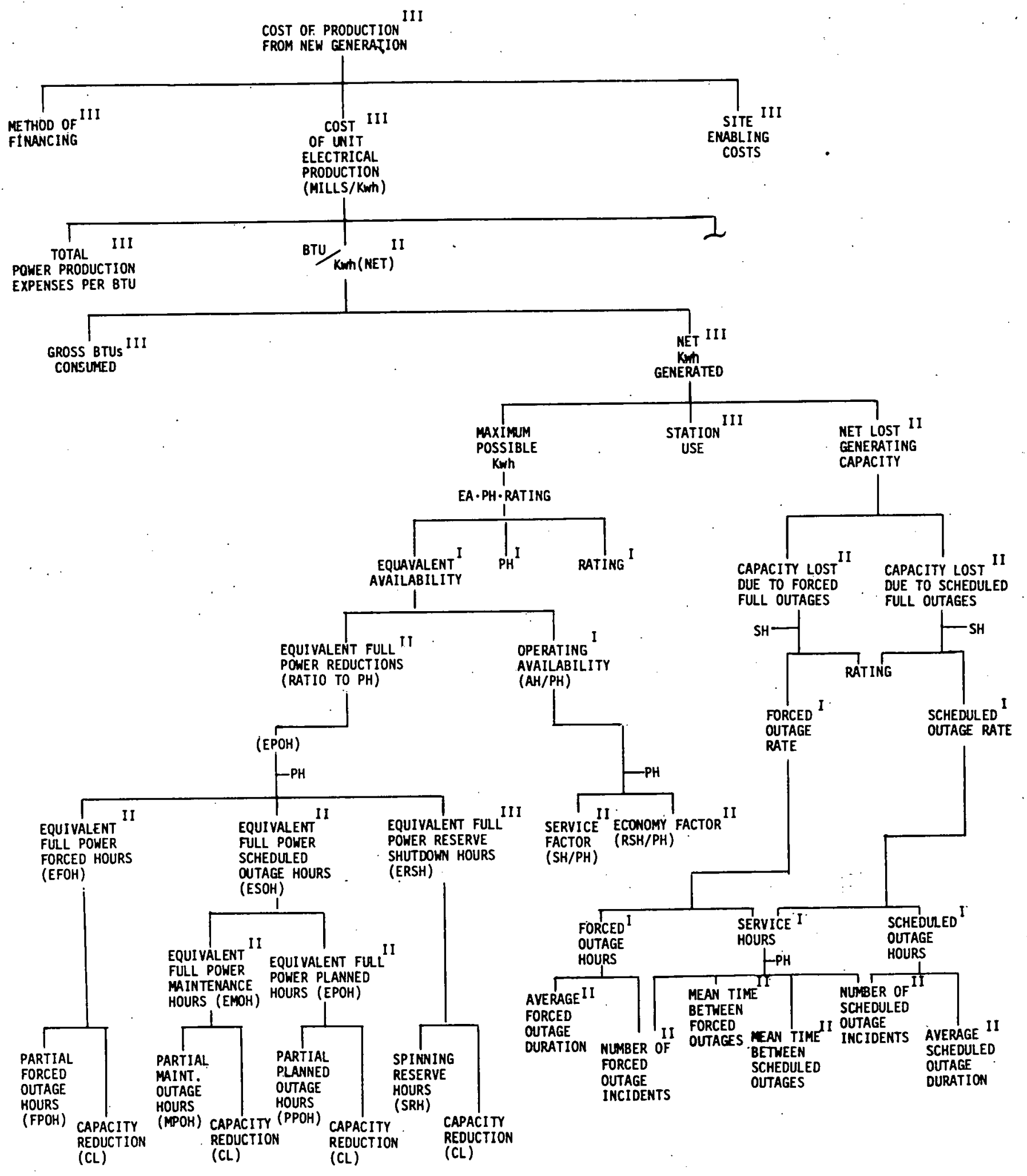

Figure 2: Influences Internal to a Plant 
electric power industry for which there is a data base for historical reference. Each indicator on the figure is coded ( $I$, II, III) to identify the degree to which data are available in the national data sources accessed for this study.

The coding used on the figure is: I for indicators directly available from one or more national sources; II for indicators which may be calculated from data which are directly available from one or more national data soureces, and III for indicators which may also be calculated but data on which is currently not available in any of the national data soureces.

A variety of additional indicators have been used by others to measure or evaluate the type and level of performance of electrical supply and distribution systems, utilities and power plants. The majority of those indicators would, however, be coded II or III, indicating that they are not directly accessible from national sources.

Historically, there are many indicators which have been used in an attempt to measure or assess power generating performance: From among those various indicators, there are several that provide a meaningful and positive reterence of the historical performance achleved by a broad range o $\vec{F}$ power plant fuel types and sizes. These specific indicators (defined by the Edison Electric Institute) are as follows:

- Capacity Factor

- Equivalent Availability

- Forced Outage Kate

- Operating Availability

- Service Factor

- Forced Partial Outage Hours

- Scheduled Partial OUtage Hours

- Forced Outage Hours

- Scheduled Outage Hours 
Table 2: Common Power Plant Terminal Measures Related to Siting Decisions

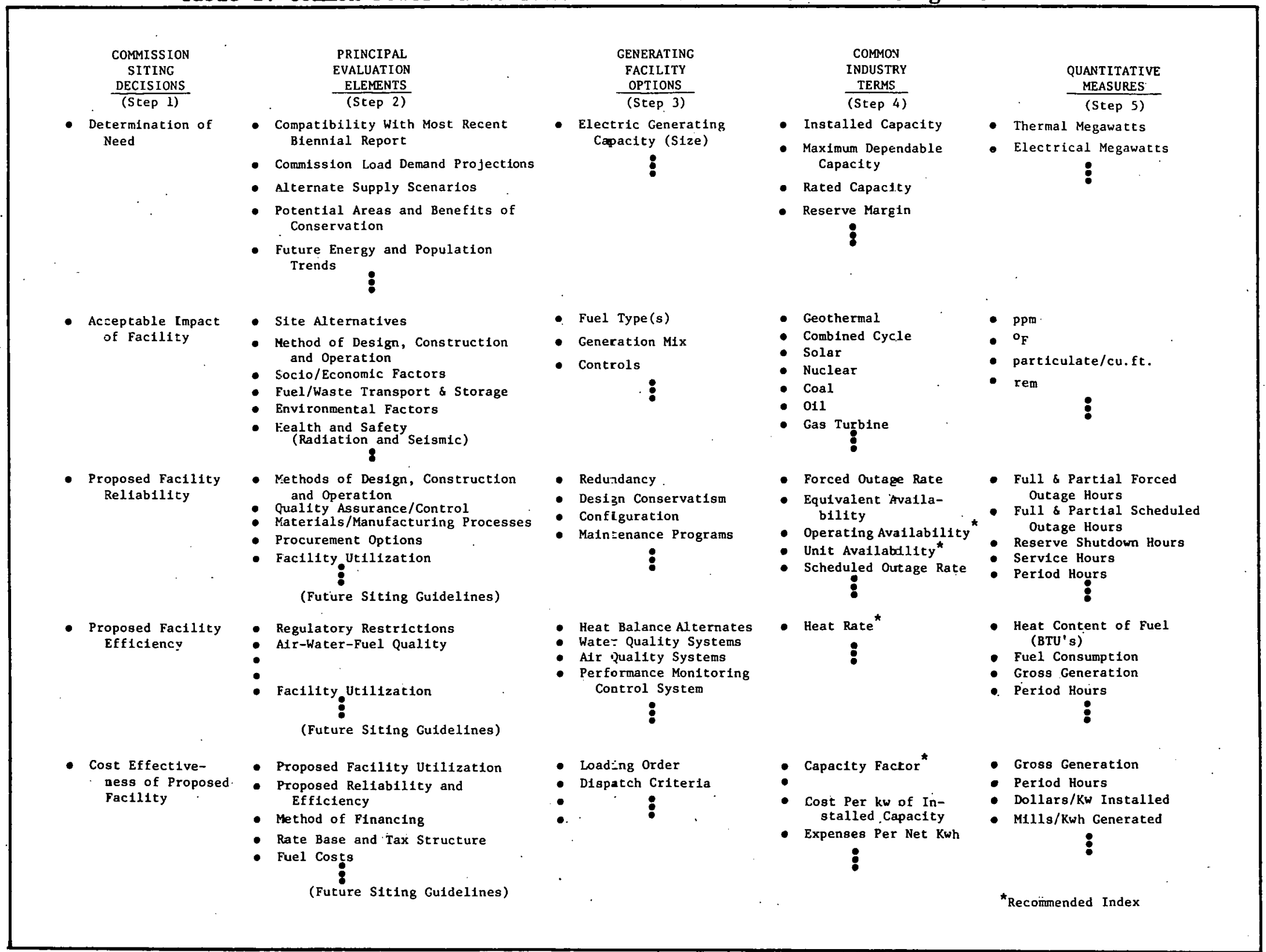


Other indicators which are available from the Federal Power Commission are:

$$
\begin{aligned}
& \text { * - Cost of Unit Electrical Production (mils/Kwh) } \\
& \text {. (Available only on a station basis) } \\
& \text { * - Gross Annual Heat Rate (BTU/Kwh) } \\
& \text { (Available for selected units only) }
\end{aligned}
$$

'The method of identification of Indices of reliability and efficiency, that could be used to satisfy Commission siting decision information requirements, involved the following six steps:

Step 1. . Review and evaluation of the "Warren-Alqu1s 2 State Energy Resources Conservation and Development Act" for the purpose of identifying major decisions which the Commlssion has to reach with respect to new facility. (power plant) siting.

Step 2. - Determination of the principal elements which the Commission needs to evaluate before making an informed decision.

Step 3 . . Identification of operational and alternative approaches available to the Commiesion in its evaluation of the principa? decision elements. These approaches cover the areas of facility design, utilization, generation, etc.

Step 4 . . Identification of the terms most commonly used in the power industry to describe the facility operations of step 3.

Step 5 . - Identification of the common measures which are nominally used to. quantify the industry terms (Step 4) as they relate to a major siting decision (Step 1).

Step 6 . - Evaluation of the measures of Step 5 to determine which of the common industry terms of Step 4 are the most logical, reason- 
Section 2.0 APPROACH TO THE SELECTION OF R\&E INDICES (Continued)

able and meaningful for consideration in the evaluation of an AFC submittal to the Commission: These terms then will be defined as indexes, and recommended for use.

This six step approach was used to establish a direct relationship between siting decision information requirements and the specific indices of power plant reliability and efficiency identified after the evaluation of available R\&E indices. An overview of the results of these six steps is shown by Table 2; each colum heading identifies one step. Although not intended to be a comprehensive table of all the regulatory decisions necessary in the complete siting process, this table presents the format used for the organization of siting information and provides a method for consideration of alternative indices from which the recommended index list was chosen.

In narrowing the final selection of the many possible indicators of cost-effective power plant reliability and efticiency, to a select few, criteria were defined and employed. The three major elements of the criteria follow:

1. Be quantifiable for a proposed power plant

2. Be calculatable, for comparison, from historical reference data

3. Provide a quantitative method for accounting for causal relationships of utility policies and programs, facility design, operations, maintenance and utilization options, etc.

Furthermore, it was intended that each index be related to Commission policy making and their decision making process at the most appropriate level. For example, the first "decision" to be reached is whether a new power generating facility is actually required, or if viable alternatives exist. Once this decision is reached, it establishes the total amount of electrical power to be supplied from a new facility. It is consistent then, to use a proposed capacity factor as an index to assess the electrical power that will be available for distribution in accordance with the Commission assessment of the actual electrical power required to meet demand. 
Operating availability and equivalent availability provide the Commission with indexes appropriate for both decision making relative to the generation time period required for meeting electrical demand and oversight of the factors which affect plant reliability (full and partial outages). Using these indexes, the Commission will be in a position to reach an informed decision as to:

1. wheather the proposed size, fuel type and plant availability is appropriate to achieve the electrical requirements of the facility, and

2. whether sufficient attention has been directed to the factors which affect plant outages (e.g., plant design rellability, planned maintenance programs, equipment reliability, testing programs, quality assurance, etc.).

Heat rate is the best indicator of how efficiently a plant design is utilizing fuel. By using this Index in conjunction with capacity factor, the Commission can determine if plant design is appropriate for the intended application. 
SECTION 3.0

PLANT CAPACITY FACTOR 
Capacity factor is one of the most commonly used terms by utilities; regulators and investigators in the electric power industry. By itself, capacity factor is simply an index of production utilization. It is used in two separate ways, (1) to describe the percentage of capacity actually realized at an existing facility, and (2) to estimate the available generation, from existing and proposed units, in the preparation of resource and load forecast projections. Unit capacity factor, actual or projected, has little meaning without information on the size of the facility, type of fuel used, cost of production, unit age, etc. When appropriately qualified and viewed in conjunction with system load factors, peak demand, available generation mix and differences in production cost efficiencies, capacity factor (àchieved or planned) takes on a more significant meaning. It becomes meaningful because it provides a shorthand method for comparing and evaluating the cost-effectiveness of both historical production utilization and planning future generation expansion of the power generation and supply system.

As an index of production utilization, capacity factor is expressed as a percentage, calculated as the ratio of electrical generation during a preestablished period of time, to the maximum possible generation during the same time period.

\section{Capacity factor $=\frac{\text { Actual Generation }}{\text { Maximum Possible Generation }}$}

It is widely recognized that several different definitions have been in use to compute the historical capacity factor of a unit. These are listed in Table 3. The first two definitions require the computation of capacity factor based upon "net" generation. Thir other three are based upon "gross" generation. The difference between "gross" and "notg" generation is the energy requirement of the unit itself. Capacity factors based upon net generation take into account the energy consumed by the unit while generating electric power. Using definftions based on net generation will, thus, provide a more accurate measure of the generation capacity that was and will be available to meet consumer need. 


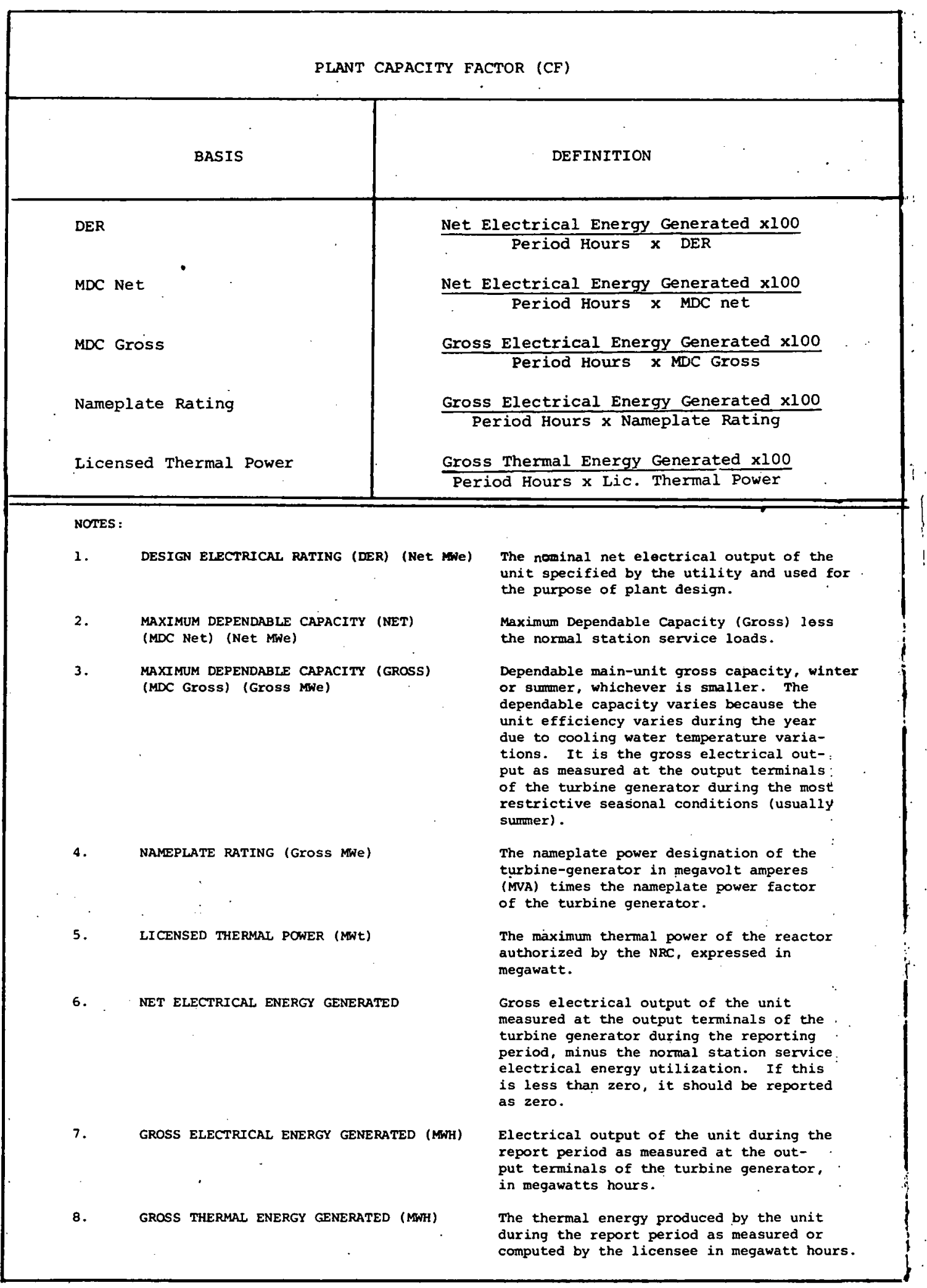


Capacity factor based upon the "gross" generation typically gives higher estimates than those based on "net" generation. Spot checks of published data of annual capacity factors for the same nuclear units have revealed that "gross". capacity factors may exceed the "net" capacity factors by ten percent (10\%) or more. Using data based upon "gross" generation can result in the erroneous impression that power plants are being better utilized.

The Commission is charged with the responsibility of ensuring that, when required, more efficient and reliable power plants will be constructed and utilized in the most cost-effective manner. Thus, the raparity factor definition suited to the needs of the Commission has to be based upon capacity factors computed using "net" generation, i.e.

$$
\text { Capacity Factor, CF }(\text { Net })=\frac{\text { Actual Net Generation }}{\text { Maximum Possible Net Generation }}
$$

The above definition of capacity factor, based upon net generation, can yield more than one value depending upon how the denominator "maximum possible net generation," is computed. Two different methods are.available, (1) based upon an assigned net maximum dependable capacity (MDC-Net) for the plant, and (2) the design electric rating (DER) of the plant.

The net maximum dependable capacity ( $M D C-N e t$ ), is defined as the smaller of the winter or summer dependable main-unit capacity. It is the gross electrical output, as measured at the output terminals of the turbine generator during the most restrictive seasonal conditions (usually summer), less the normal electrical requirements of the unit.

The design electrical rating (DER) is the theoretical "net" electrical output of the unit specified by the utility and used for the design of the plant. The maximum dependable capacity is often less than the unit design electrical rating. The as-built unit capability may not precisely meet the original design projections (specifications) because of regulatory restrictions, environmental 11mitations, etc., that limit the maximum output of a unit. 
For reaching decisions on the need for new electrical generation capacity, the Commission must necessarily focus on the block of power that will actually be available for distribution to the consumer, as measured by the capacity factor projected for the new facility. In keeping with this requirement it is necessary to assure that a planned facility will provide the required capacity, In addition the Commission's mandate also requires that this power be provided in the most cost-effective manner consistent with the highest levels of reliability and efficiency. For this purpose, then, capacity factor computed on the basis of the design electrical rating ensures, at least in theory, that the efficiency level designed into the plant can be monitored and maintained, e.g, , as the operating efficiency decreases, the achievable capacity will also decrease, and the Commission can monitor these reductions. Capacity factors computed on the basis of maximum dependable capacity provide no such insight on the efficiency levels to the Commission. The recommended definition of capacity factor, for use by the Commission is:

$$
\text { Capacity Factor }=\frac{\text { Actual Net Generation }}{\text { Period Hours } \times \text { Design Electrical Rating }}
$$


There are three sources of capacity factor data - the Nuclear Regulatory Commission (NRC), the Edison Electric Institute (EEI) and Utility/plant management personnel. The NRC collects monthly and annual capacity factor data for nuclear power plants only. Before January 1977 it collected monthly and annual capacity factor data computed on a plant's Design Electrical Rating (DER) and the Maximum net Dependable Capacity (MDC-net). Starting with January 1977, the NRC has started to collect individual nuclear plant capacity factor data computed based also upon the gross Maximum Dependable Capacity (MDC-gross), the plant Nameplate Rating and its Licensed Thermal power.

The Edison Electric Institute (EEI) collects annual capacity factor data on Coal fired, nuclear, oil fired, gas fired plants and gas turbines. The EEI data bank contains capacity factor data computed using plant gross Maximum Dependable Capacity (MDC-gross) from 1965 for most plants. As EEI membership and annual utility data reporting requirements are voluntary, the EEI data bank does not contain capacity factor data on each plant in the U.S. for every year of operation.

Capacity factor data on geothermal and combined cycle plants are only available through the operator utility or plant personnel. Supporting data to base the calculation of capacity factor on DER, MDC-net, MDC-gross, Nameplate Rating are all available.

The fundamental problem with the recommended definition of capacity factor (based upon plant Design Electrical Ratings) is the lack of historical capacity factor data to arrive at a meaningful evaluation of a proposed capacity factor. While capacity factor data computed on Design Electrical Rating are available for nuclear planțs from the NRC, the Design Electrical Rating for fossil plants. is not readily available. This limits the use of the recommended definition of capacity factor. The most comprehensive source of capacity factor data is the EEI but, as has been discussed earlier, their estimates are computed using gwoss electrical generation. 
Table 4: Capacity Factor Data Sources

\begin{tabular}{|c|c|c|c|}
\hline \multicolumn{4}{|c|}{ UNIT CAPACITY FACTOR } \\
\hline \multirow{2}{*}{$\begin{array}{c}\text { Basis of } \\
\text { Computation }\end{array}$} & \multicolumn{3}{|c|}{ Data Source } \\
\hline & $\mathrm{NRC}^{\dagger}$ & EEI* & Utility Unit** \\
\hline DER & $x^{\dagger+}$ & & $x$ \\
\hline MDC-Net & $x^{+t}$ & & $\mathrm{x}$ \\
\hline MDC-Gross & $x^{+\dagger+}$ & $\mathrm{x}$ & $x$ \\
\hline Nameplate Rating & $x^{t+t}$ & & $\mathrm{x}$ \\
\hline $\begin{array}{l}\text { L1censed Thermal } \\
\text { Power }\end{array}$ & $x^{++t}$ & & $\mathrm{x}$ \\
\hline $\begin{array}{l}\text { †Nuclear units } \\
++ \text { From date of } \\
+++ \text { Since } 1977 \text { on } 1 \\
{ }^{\star} \text { Since } 1965 \\
{ }^{\star} \text { Since date of }\end{array}$ & lal & ion & \\
\hline
\end{tabular}

Table 5: Unit Capacity Factor Data Sources

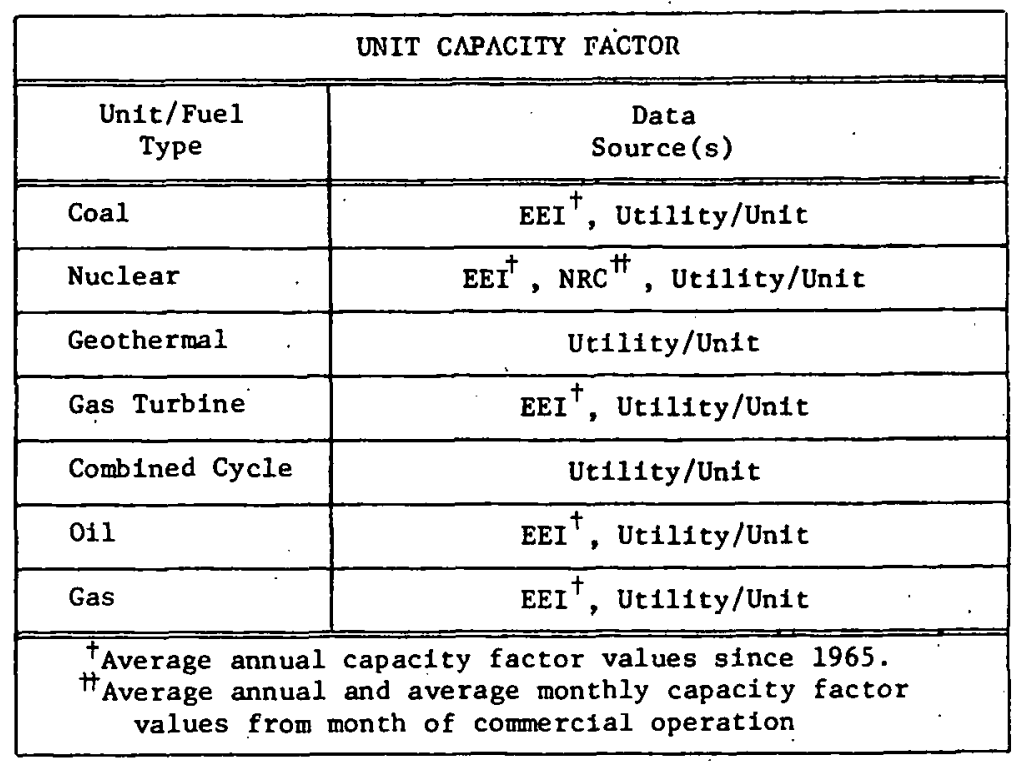


Section 3.0 PLANT CAPACITY FACTOR

Subsection 3.3 Recommendation For Application

Capacity factor data can be used by the Commission to evaluate the losses (decrease in power plant generation), due to outages and power reductions. Figure 3 presents a method of accounting for the loss of power plant capacity. This method can be used to monitor and assess all influences on power plant productivity. In the example shown, a capacity factor "loss" of $45 \%$ is assumed for the period: $33 \%$ of the loss is due to full forced and scheduled outages of the unit; and $12 \%$ of the loss is due to power reductions caused by (1) lack of demand, $.5 \%$, (2) regulatory constraints, $1 \%,(3)$ economic dispatch considerations, $1 \%$ (e.g., either a more efficient unit was used or less expensive power was purchased), (4) reductions in unit thermodynamic efficiency, .5\%, (e.g., cooling water ambient temperature increases), and (5) forced or scheduled partial outages which account for $2 \%$ and $7 \%$ of lost capacity, respectively. The figure can easily be extended further to highlight specific systems, equipment or unit conditions for each of which losses of generation may be assessed.

In showing the principal elements which affect capacity factor, Figure 3 provides an excellent overview of the many factors to be considered, and controlled, if high capacity factors are desired. As a tool in the planning and evaluation of alternate generation expansion senarios, and for monitoring the performance of a new generating facllity, this method of accounting for potential or actual capacity losses has extensive usefulness. For example, the factors which affect the elements of Figure 3 involve all aspects of design, construction, operation, maintenance and utilization of the facility. The Commission will require positive assurance that each utility has given careful consideration to the control and administration of these areas.

One of the primary uses of historical capacity factor data is the insight they provide through comparison with projected capacity factors of similar units. Instances where the proposed capacity factor is equivalent to the historical capacity factor achieved by a power plant indicate that the proposed plant will probably achieve its planned generation goal. Similarly, the proposed capacity factor can be very much lower than the historical values or can greatly exceed 


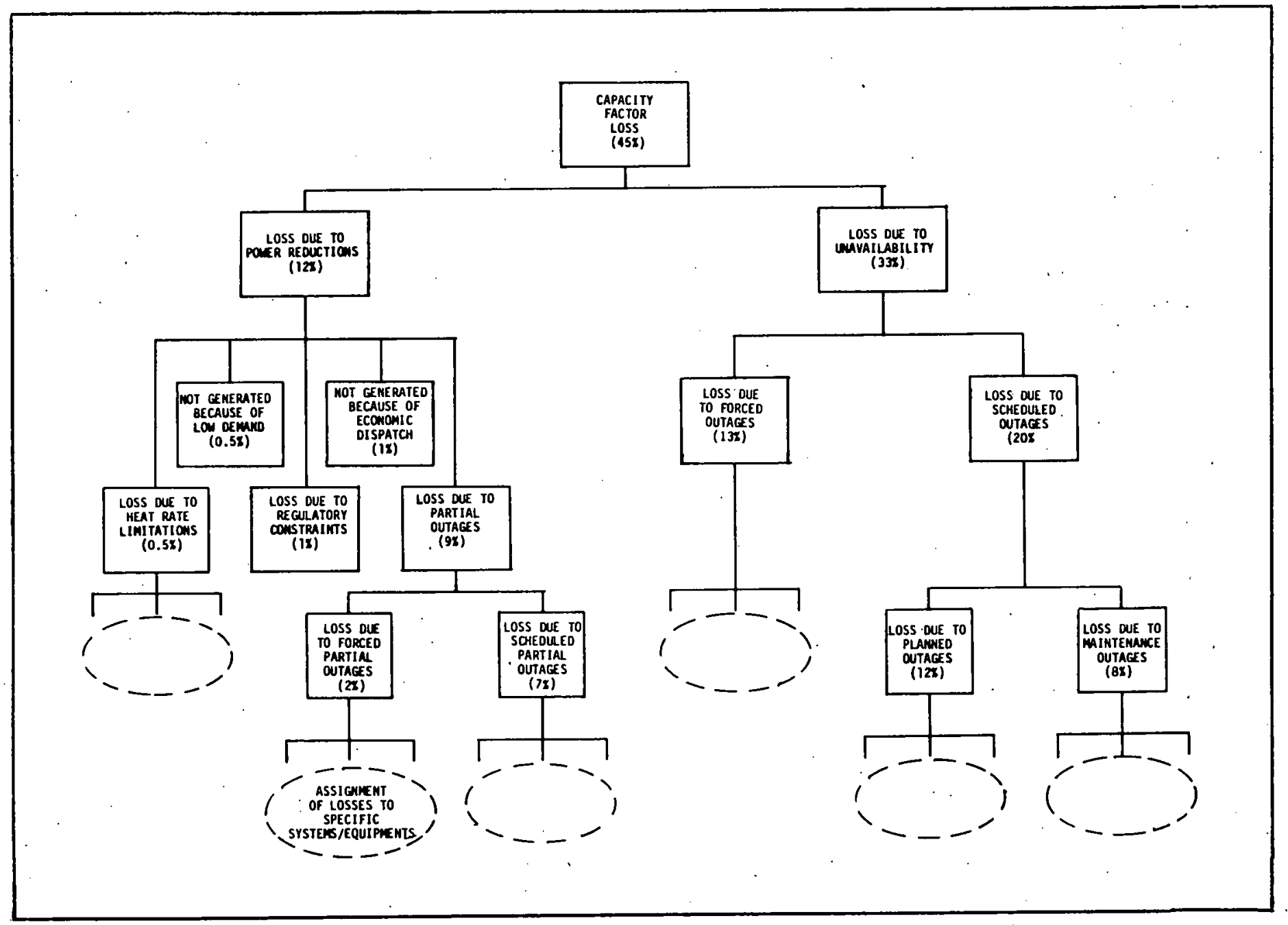

Figure 3: Method of Accounting for Capacity Factor Loss 
them. In the former case, the chosen plant would not be effectively utilized and additional effort would be recommended to arrive at a better match between projected capacity factor and plant installed capacity.

When historical values of capacity factor are greatly exceeded by projected capacity factors it is necessary to review the historical data. Historical capacity factors can be low because of many reasons, e.g., installed capactty greatly exceeds need, plants are either immature or too old, etc. While these: preliminary conclusions provide a rough estimate of the adequacy of the proposed plant size and type, these conclusions can be further refined and substantiaced by using the capacity factor index along with the other three recommended indices. A discussion of various combinations of the recommended indices is provided in section 7.0 . 
SECTION 4.0

PLANT OPERATING AVAILABILITY 
Section 4.0 PLANT OPERATING AVAILABILITY

Subsection 4.1 Definition.(s)

Operating Availability as it is called by EEI, of Unit Availability as it is called by the $\mathrm{NRC}$, is an index of productive capacity readiness or preparedness (i.e. a measure of a power plant's availability to generate some electric power). Operating Availability is a time dependent index. As defined by both EEI and NRC, operating (Unit) availability is calculated as the ratio fo the total plant operating time (service hours) plus standby time (reserve shutdown hours), to the total calender time for the period (period hours).

$$
\begin{aligned}
& \text { Operating Availability }=\frac{\text { Service Hours + Reserve Shutdown Hours }}{\text { Period Hours }} \\
& \quad \mathrm{OA}=\frac{\mathrm{SH}+\mathrm{RSH}}{\mathrm{PH}}
\end{aligned}
$$

As shown by the above equation, operating availability is a measure of the time a power plant could be in service. It is independent of the output power level of the plant ie. operating availability provides no insight into the gross generation capacity (historical or projected) of a power plant.

Figure 4 illustrates the interelationship of the various time periods comprising the period hours ( $\mathrm{PH})$. Operating Availability, as defined above and shown in the figure, provides information on the percentage of the period hours for which a power plant is capable of generating some electric power and the percentage of the period available to accommodate full forced and full scheduled outages. The outage time for large baseloaded units is usually reserved for planned annual maintenance and overhaul of major plant equipment; additionally, unplanned maintenance requirements, (e.g. full forced outages due to equipment failure) are also included in this time period. Operating availability does not provide any Information to help distinguish between forced and scheduled outage times. It just bounds the total allowable outage time. Operating availability also does not provide any insight into partial outages, their time requirements or the reduction in plant capacity. 


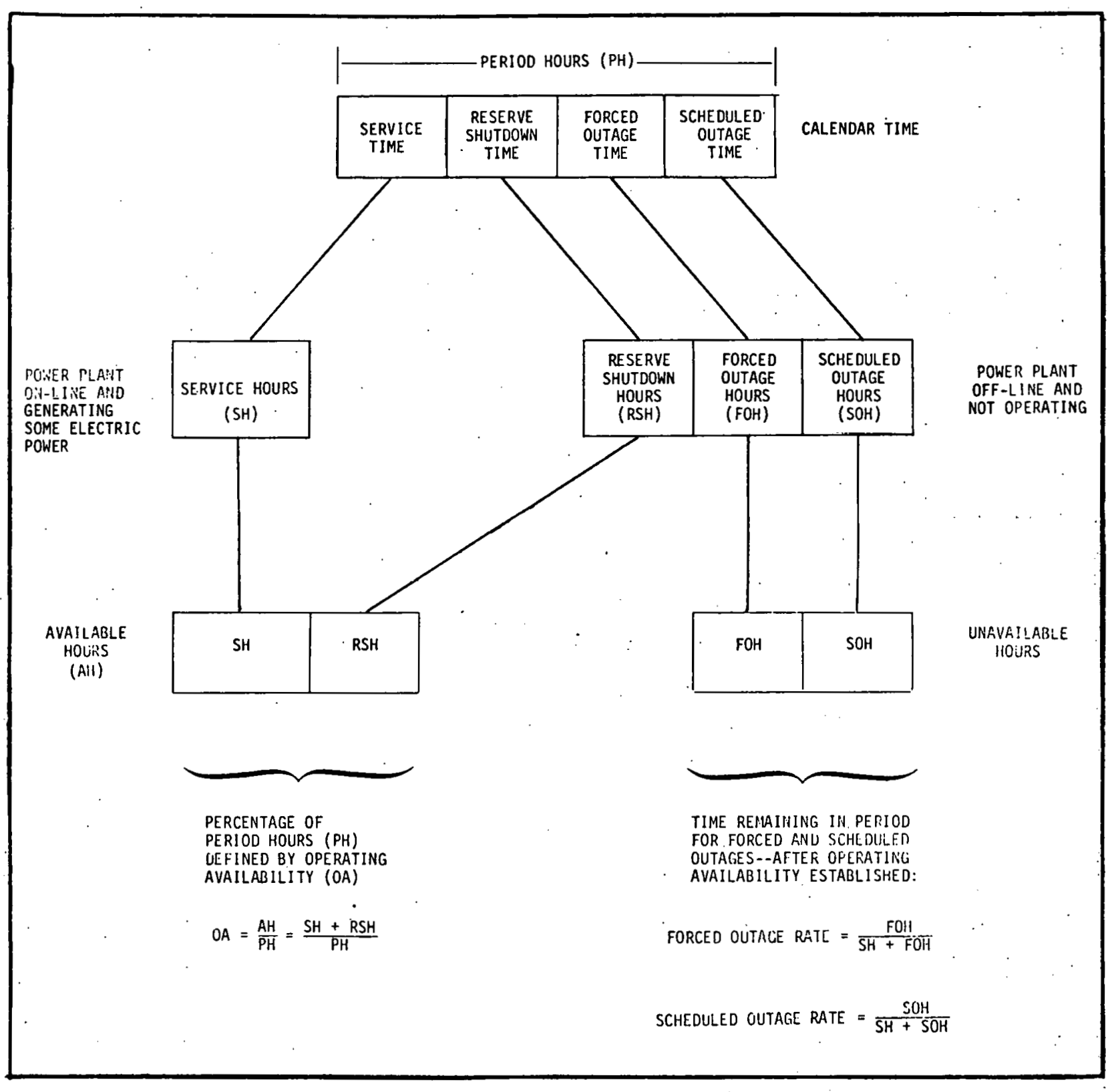

EEI DEF INITIONS:

*Service Hours (SH)

The total number of hours the unft was actuilly operated with breakers clused to the station.

*Reserve Shutdown Hours (RSH): Reserve Shutdown duration in hours

*Reserve Shutdown:

The removel of a dis The removal of a unit from review for econom but available for operation.

Figure 4: Operating Availability Definition 
Section 4.0 PLANT OPERATING AVAILABILITY

Subsection 4.2 Data Availability/Sources

There are three primary sources of historical operating availability data, nameiy, the Edison Electric Institute (EEI) Equipment Availability data bank, the Nuclear Regulatory Commission (NRC) and the plant operator Utility/Unit personnel. The Edison Electric Institute cullects annual operating ava1lab1lity data on gas turbines, coal fired, gas.fired, oil fired and nuclear power plants. The historical data for each plant is available to the EEI member utilities. Annual average operating availability data by plant type, fuel type, plant size etc. are also available." As membership in the EEI is voluntary, data on a11 plants are not available for each year of commercial operation.

The Nuclear Regulatory Commission (NRC) collects monthly and Annual average operating availability data for nuclear plants only. The NRC "Unit Status Report" does, starting with Jan 1977, contain same EEI summeries of average annual operating availabilities for different plant fuels and types.

For the historical data on operating availability of existing power plants to be useful in projecting feasible operating availability levels for new power plants it Is necessary to analyse this historical data. This analysis is required to focus not only upon the historical operating availability but is required to evaluate the service hours, reserve shutdown hours, and the total nutage hours in any period.' Reserve shutdown hours have not been regularly documented for al1 plants in the data systems. Furthermore, no documentation is available to verify that plants reported to be in reserve shutdown could actually be used to generate power and that the reserve shutdown periods were not used to performs. repairs or routine preventative maintenance on plant components/systems. 
Table 6: Operating Availability Data Sources

\begin{tabular}{|c|c|}
\hline \multicolumn{2}{|c|}{ PLANT OPERATING AVAILABILITY } \\
\hline $\begin{array}{c}\text { Unit/Fuel } \\
\text { Type }\end{array}$ & Data Source(s) \\
\hline $\begin{array}{l}\text { COAL } \\
\text { NUCLEAR } \\
\text { GEOTHERMAL } \\
\text { GAS TURBINE } \\
\text { COMBINED CYCLE } \\
\text { OIL } \\
\text { GAS }\end{array}$ & $\begin{array}{l}\text { EEI }^{+}, \text {UTILITY/IINIT } \\
\text { NRC }^{+} \text {, EEI }{ }^{+} \text {, UTILITY/UNIT } \\
\text { UTILITY/UNIT } \\
\text { EEI }^{+}, \text {UTILITY/UNIT } \\
\text { UTILITY/UNIT } \\
\text { EEI }{ }^{+}, \text {UTILITY/UNIT } \\
\text { EEI }^{+}, \text {UTILITY/UNIT }\end{array}$ \\
\hline $\begin{array}{l}+ \text { Average ann } \\
+ \text { Average mon } \\
\text { commercial }\end{array}$ & $\begin{array}{l}\text { values since } 1965 \\
y \text { and annual values from date of } \\
\text { ration }\end{array}$ \\
\hline
\end{tabular}


Section 4.0 PLANT OPERATING AVAILABILITY

Section 4.3. Recommendations for Application

The index Operating Availability can be used to (1) describe the historical percentage of time a specific power plant has been available and (2) to estimate the required availability of a proposed facility to meet electrical demand projections.

As an index to be used in the siting process, operating availability provides a method for fixing or bounding the periods of electrical generation and nongeneration (e.g., full outages). Figure 4 illustrates this by showing the interrelationship of the major calendar time elements which comprise availability and unavailability.

Projection of the required operating availability for a new power plant will establish the percentage of time during a period (generally one year) the plant is capable of producing electric power. Once operating availability is established, as shown by Figure 4, the time remaining for scheduled outages and forced outages is also established. The Commission should examine operating availability projections from the following viewpoints:

1. The basic design, construction, operation, maintenance, etc., must be reviewed to assure that the proposed operating availability will be acheived, and,

2. The design conservatism and proposed maintenance planning and scheduli.ing must be reviewed to assure that full forced outages will. he minimized and that scheduled outage management and control will be conducted effectively to keep within the planned unavailability time.

Figure 4 also presents the EEI defined method for calculating forced outage rate (FOR) and scheduled outage rate (SOR). Figure 5 illustrates the "bounds on each outage rate for a wide range of operating availability values. The dashed lines on the figure show that if the Forced outage rate is projected at $5 \%$ then for an operating availability of $95 \%$ there will be no time available for scheduled outages (i.e., $0 \%$ SOR): Similarly, for required operating 


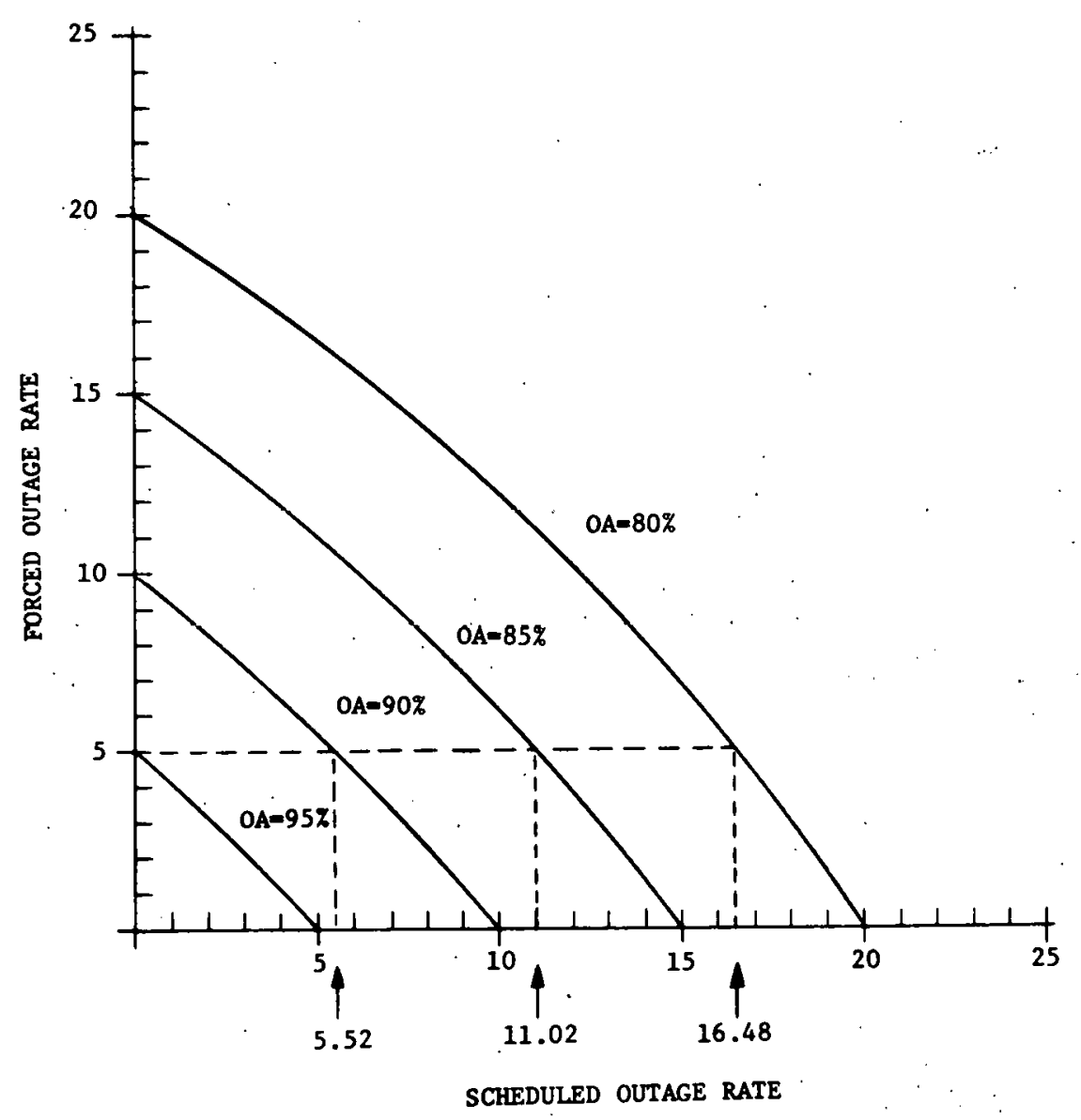

Figure 5: Operating 1 vailability and Outage natce 
Section 4.0 PLANT OPERATING AVAILABILITY

Subsection 4.3 Recommendation for Application (Continued)

availabilities of $90 \%, 85 \%$ and $80 \%$, the maximum SOR's will be $5.52 \%, 11.02 \%$ and $16.8 \%$, respectively. The EEI definitions have been used for this illustration because data are available from EEI on forced outage rates for historical comparison on a wide range of unit sizes and fuel types. 
SECTION 5.0

PLANT EQUIVALENT AVAILABILITY 
Section 5.0 PLANT EQUIVALENT AVAILABILITY

Subsection 5.1 Definition(s)

As defined by the Edison Electric Institute (EEI), Equivalent Availability is the "equivalent" percentage of time that a generating unit is available to operate at full power. In the EEI approach, for any historical time period being considered, EA is computed by subtracting from the available hours in the period the "equivalent" number of full power outage hours (scheduled + forced) contributed by partial outages. This latter term is computed by multiplying the "weighted" capacity loss for each partial outage by the number of hours of that. outage. The resultant is divided by the total number of hours in the period to obtain the EA. The weighting factor for a partial outage is determined by the power level available during that outage. For example, operation for two hours at $75 \%$ of full power is a partial outage which is "equivalent" to a total outage of one-half hour because the same total energy would be produced in both cases. The computation of equivalent availability is thus, a measure of the time the power plant is available during the period to operate at full power. Equivalent availability 主s expressed mathematically às follows:

Equivalent Availability $=$ Available Hours $-\left\{\begin{array}{l}\text { equivalent ful\} } \\ \text { power forced } \\ \text { ontage hours }\end{array}\right\}\left\{\begin{array}{l}\text { equivalent full } \\ \text { power scheduled } \\ \text { outage hours }\end{array}\right\}$

Period Hours

Figure 6 illustrates the interrelationship of the various time elements comprising the period hours. Equivalent availability, as defined above and shown in the figure, provides information on 1) the percentage of the period hours for which a power plant is capable of generating full. power, and 2) the percentageof the period hours available to accommodate full and partial outages. Equivalent availability does not provide any insight into the percentage of the period hours available to accommodate partial outages and full outarges seperately. 


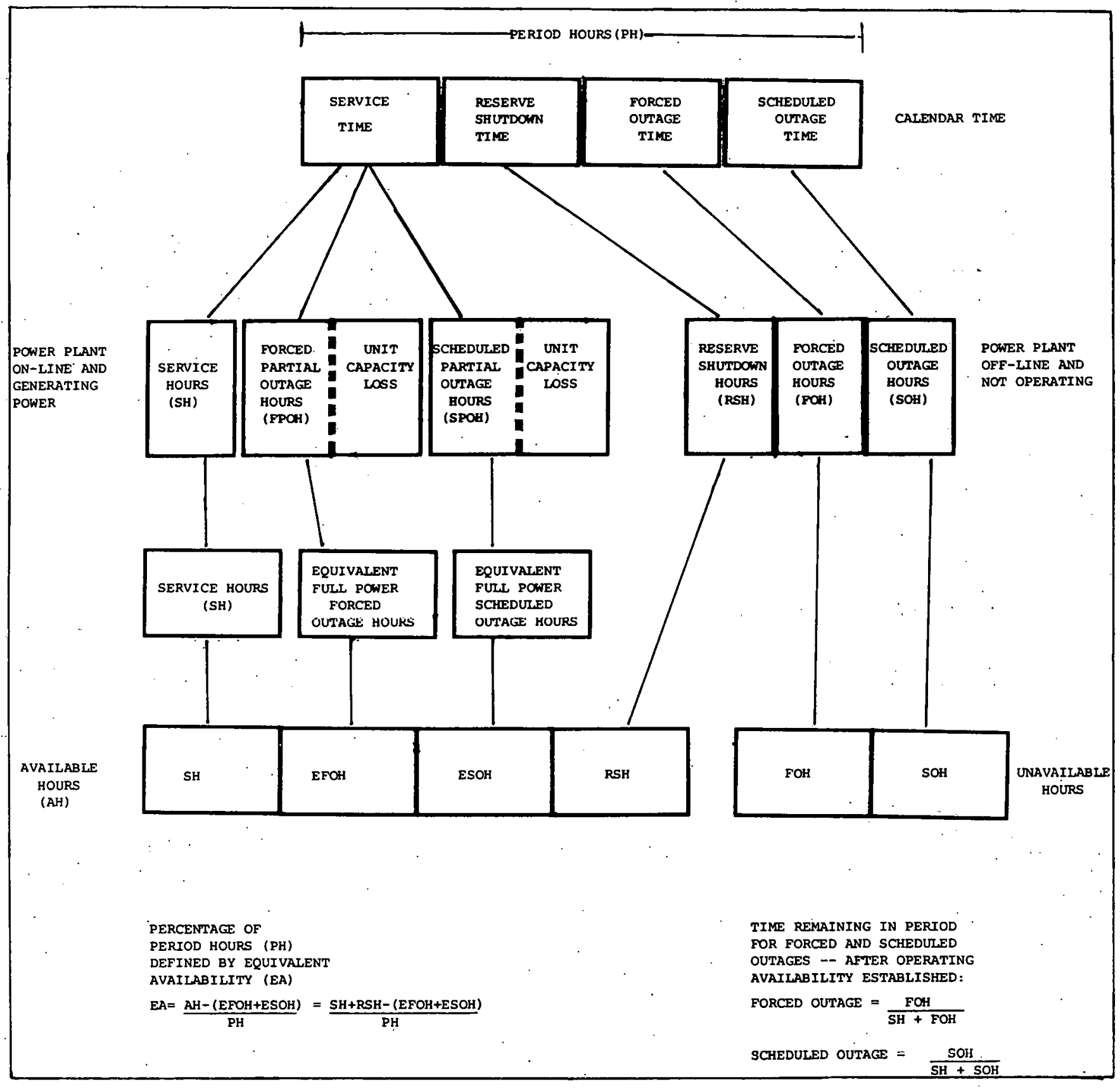

EEI DEFINITIONS:

*SERVICE hours (SH)

THE TOTAL NUMBER OF HOURS THE UNIT WAS ACTUALLY OPERATED WITH BREAKERS CIOSEN TO THE STATION BUS.

* RESERVE SHUTDOWN HOURS (RSH)

RESERVE SHUTDOWN DURATION IN HOURS.

-RESERVE SHUTDOWN

THE REMOVAL OF A UNIT FROM SERVICE FOR ECONOMY OR SIMILAR REASONS THIS STATUS CONTINUES AS LONG AS THE UNIT IS OUT BUT AVAILABLE FOR OPERATION.

Figure 6: Equivalent Availability Definition 
Section 5.0 PLANT EQUIVALENT AVAILABILITY

Subsection 5.2 Data Availability/Sources

The Edison Electric Institute's Equipment Availability data bank is the only data bank nationwide that collect historical equivalent availability data. EEI collects annual equivalent availability data on nuclear plants, coal, oil, and gas fired plants and gas turbines. It publishes annual average equivalent availability by different plant/fuel types, and by different plant size.

The EEI definition of equivalent availability has remained unchanged over the years but its method of computation has changed. Before 1976, equivalent availability was computed by subtracting from the service hours in a period, the "equivalent" number of full puwer uulage livurs, and dividing the rocult by the period hours. This computation can be expressed mathematicaliy as follows:

$$
\text { Equivalent Availability }=\frac{\text { Service Hours }-\left\{\begin{array}{l}
\text { Equivalent full power } \\
\text { outage hours }
\end{array}\right\}}{\text { Period Hours }}
$$

Since 1976, the equivalent availability has been computed by subtracting from the Available Hours (Service hours plus reserve shutdown hours) in a period, the "equivalent" number of full power outage hours; and dividing the result by the period hours. This computation can be expressed mathematically as follows:

$$
\begin{aligned}
\text { Equivalent Availab1l1ty } & =\frac{\text { Available Hours }-\left\{\begin{array}{l}
\text { Equivalent full } \\
\text { power ourage houre }
\end{array}\right\}}{\text { Period Hours }} \\
= & \frac{\text { Service hours }+ \text { Reserve Shutdown hours }-\left\{\begin{array}{l}
\text { Equivalent } \\
\text { full outage } \\
\text { hours }
\end{array}\right\}}{\text { Period Hours }}
\end{aligned}
$$

It. Is recommended that the Commission use the latter (current) meithod for computing equivalent availability: Data currently available (1977, 1976 and pre 1976) has' been corrected by EEI to comply with this new method of computation. The reader is cautioned against using data in old EEI reports and other literature, as the annual average equivalent availability data contained in theseseports and literature may be computed based upon the service hours only. 
Section 5.0 PLANT EQUIVALENT AVAILABILITY

Subsection 5,2 Data Availability/Sources (Continued)

Equivalent availability data of individual plants is also available from the plant owner/operator. If equivalent availability data is not available, the back up information to compute the annual average equivalent availability is available, from the utility for most plants.

Table 7: Equivalent Availability Data Sources

\begin{tabular}{|c|c|}
\hline \multicolumn{2}{|c|}{ PLANT EQUIVALENT AVAILABILITY } \\
\hline $\begin{array}{l}\text { UNIT/ FUEL } \\
\text { TYPE }\end{array}$ & DATA SOURCE(S) \\
\hline $\begin{array}{l}\text { COAL } \\
\text { NUCLEAR } \\
\text { GEOTHERMAL } \\
\text { GAS TURBINE } \\
\text { COMBINED CYCLE } \\
\text { OIL }: \\
\text { GAS }\end{array}$ & $\begin{array}{l}\text { EEI }{ }^{\dagger}{ }^{+} \text {UTILITY/UNIT } \\
\text { EEI, }{ }^{+} \text {UTILITY/UNIT } \\
\text { UTILITY/UNIT } \\
\text { EEI },{ }^{+} \text {UTILITY/UNIT } \\
\text { UTILITY/UNIT } \\
\text { EEI }{ }^{+} \text {UTILITY/UNIT } \\
\text { EEI, }{ }^{+} \text {UTILITY/UNIT }\end{array}$ \\
\hline$t_{\text {Average annual }}$ & lues since 1965 \\
\hline
\end{tabular}


The index equivalent availability can be used to (1) describe the historical percentage of time and specific power plant has operated at its maximum rated power level, and (2) to estimate the required capabilities of a proposed. facility to meet electrical demand.

As an index to be used in the siting process, equivalent availability provides a method for fixing the maximum period of time during which the plant can operate at full power. It also bounds the total time available for full outages plus the "equivalent" time avallable for partial outages. Figure 7 shows a graph between plant equivalent availability and the equivalent full power outage time. A straight line relationship exists: As the equivalent full power outage time increases the equivalent availability reduces.

Projection of required equivalent availability is based upon the required capacity factor and the reserve requirements to be satisified by the plant. The projection of equivalent availability establishes, thus, the total generation capbility of the proposed plant and bounds the total equivalent full power outage time. The Commission should examine equivalent availability projection from the following viewpoints:

(1) the basic design, construction, operation, maintenance, etc. must be reivewed to assure that the proposed equivalent availability will be achieved, and

(2) the design, conservation and proposed maintenance planning and scheduling must be reviewed to assure the full and partial outages will be minimized and controlled effectively such that the planned equivalent full power outage time will not be exceeded. 


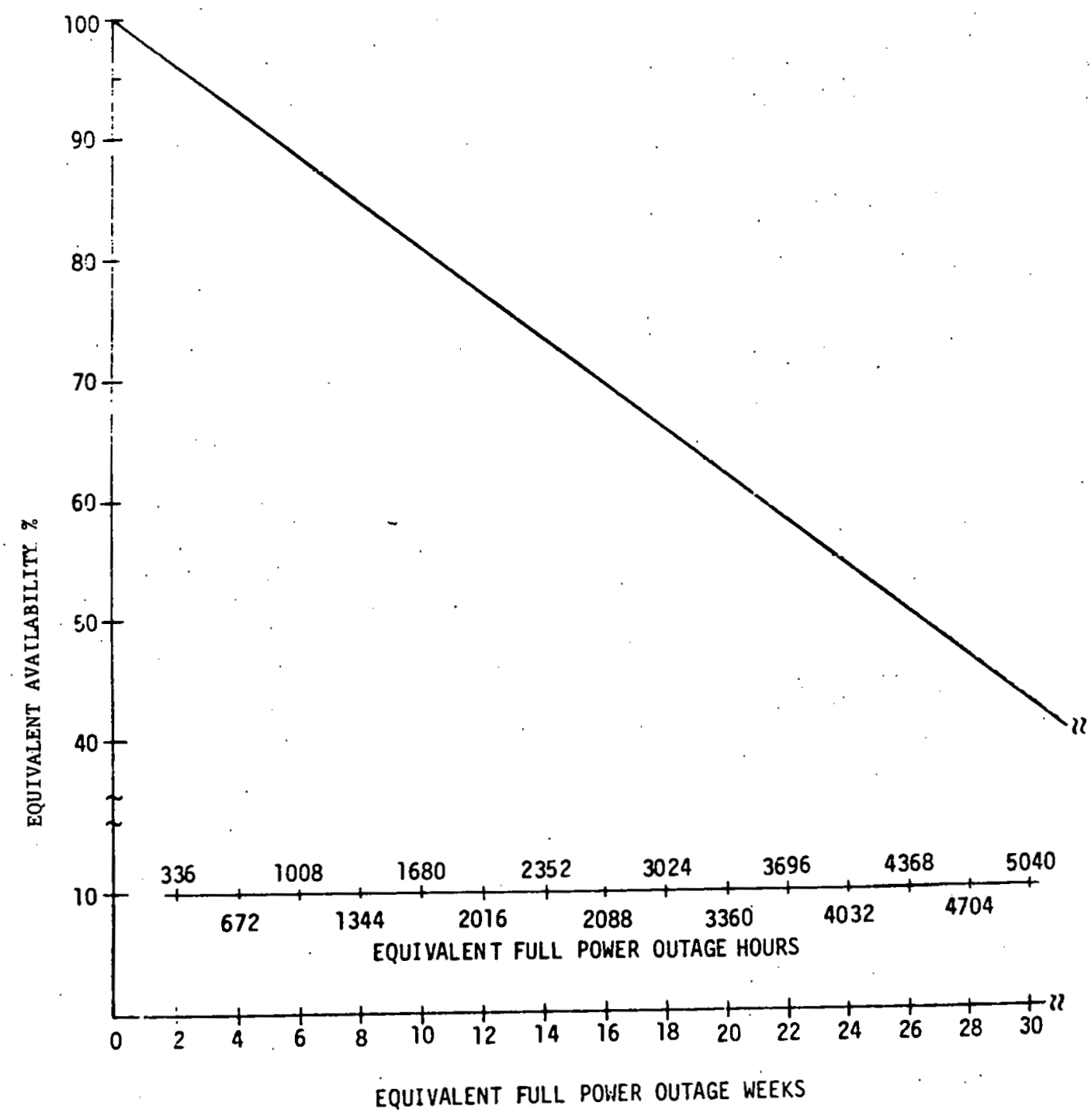

Figure 7: Effect of Outages on Equivalent Availability 


\section{THIS PAGE}

\section{WAS INTENTIONALLY \\ LEFT BLANK}


SECTION 6.0

PLANT HEAT RATE 
Heat rate is a term commonly used in the electric power industry to reference the level of thermodynamic efficiency of power plants. It is directly dependent on the efficiency of all processes involved in the conversion of primary fuel energy to electrical power. In addition, heat rate is strongly dependent on the level of power being generated at any specific instant in time. This is due to the relative inefficiencies of systems and equipment, and the basic conversion processes at different operating levels.

Heat Rate is defined in a different manner during the design of a unit than its computation during the time the unit is in commercial operation. For design purposes the turbine best heat rate at design power level is used after adjusting for boiler losses. After a unit is in commercial operation, however, Heat rate is defined as the amount of fuel energy measured in BTU's required to generate one $\mathrm{KWH}$ of electricity. It can be expressed as a ratio, as follows:

$$
\text { Heat Rate (HR) }=\frac{\cdots \text { Fuel Energy Consumed }}{\text { Electrical Energy Generated }}
$$

The term "electrical energy" in the above ratio, can be based on either "gross" electrical power or "net" electrical power. Since the true operating efficiency must necessarily consider electrical energy losses due to auxilliary equipment, plant housekeeping chores, etc., the "net" heat rate (based on net electrical energy) is recommended for the quantitative value to be used for the index. This ratio for net heat rate is defined as below:

Fuel Energy Consumed

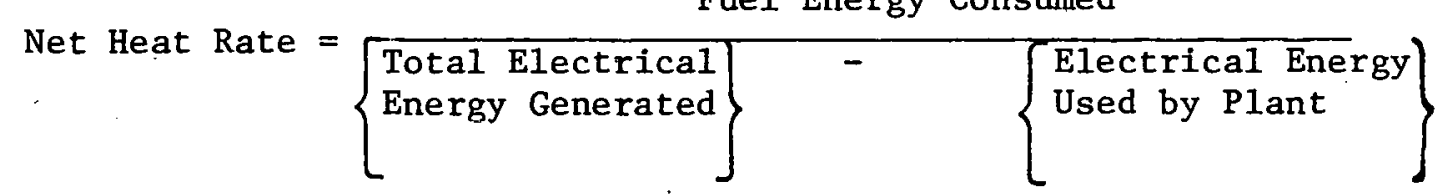

As shown in the graph on the facing page (the difference has been exaggerated) the "net" heat rate is always higher than the "gross" heat rate. 

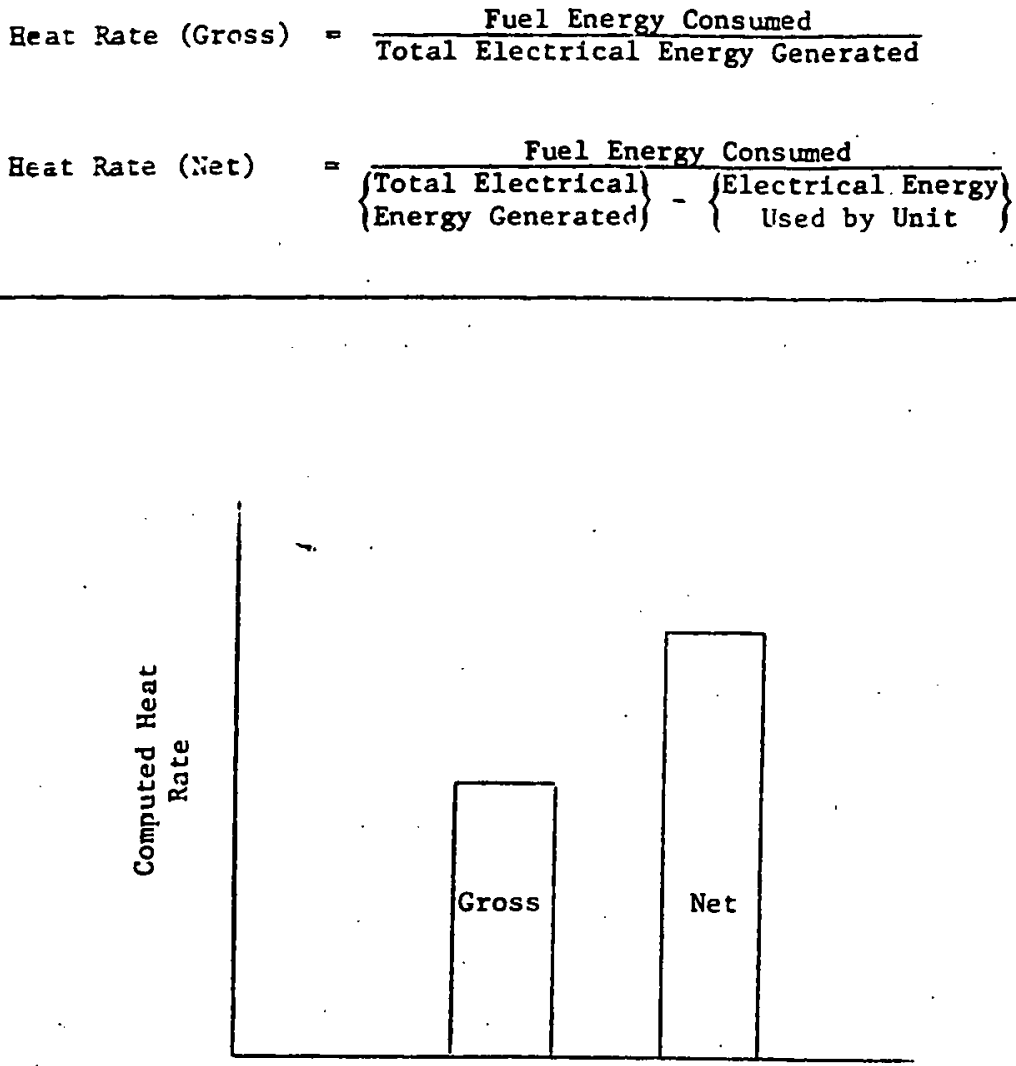

Figure 8: Definition of Heat Rate 
There are two primary sources of heat rate data - the Federal Power Commission (FPC) and utility/unit records. The Federal Power Commission collects data on "net" heat rate. This data is not available for all operating units, but is available for stations. Data is collected by the FPC on coal fired, oil fired, gas fired, nuclear units and gas turbines. The FPC currently does not collect heat rate data on geothermal units or combined cycle glants. The FPC data is contained in the "Steam-Electric Plant Construction Cost and Annual Production Expenses" supplements. These reports list annual average net heat rate for each station regardless of what fuel or combination of fuel is used. The gas turbine data is available from the "Gas Turbine Electric Plant Construction Cost and Annual Production Expenses" supplements.

Unit heat rate data is available from the FPC Form 1 and Form 1-M in which the utilities are required to report the average annual net heat rate for the most efficient generating units (not to exceed 10 in number) which were operated at annual capacity factors of fifty (50) percent or higher.

Unit "net" and "gross" heat rate data on coal, oil, gas, nuclear and gas turbines is, in general, available from utility/ünit records. Neither gross heat rate nor net heat rate data are computed for the geothermal units. The only performance related measure that is recorded is the gross steaming rate ( $1 \mathrm{~b} / \mathrm{MW}$ ). Knowing the average gross steaming rate and the average enthalpy of geothermal steam, the gross heat rate can be computed. At the geothermal units, however, the steam enthalpy is not monitored/recorded on a regular periodic basis. As a result no representative data on the annual average enthalpy of the steam utilized is available and thus no estimates of heat rate data can be made. 
Table 8: lleat Rate Data Sources

\begin{tabular}{|c|c|}
\hline \multicolumn{2}{|c|}{ UNIT BEAT RATE } \\
\hline $\begin{array}{l}\text { Unit/Fuel } \\
\text { Type }\end{array}$ & Data Source (s) \\
\hline Coal & $\mathrm{FPC}^{\dagger}$, Ut1lity/Unit \\
\hline Suclear & $\mathrm{FPC}^{\dagger}$, Ut1lity/Unit \\
\hline Geothermal & Utility/Unit \\
\hline Gas Turbine & FPC $^{\dagger}$, Utility/Unit \\
\hline Combined Cycle & Utility/Unit \\
\hline 011 & $\mathrm{FPC}^{\dagger}$, Ut1lity/Unit \\
\hline Gas & $\mathrm{FPC}^{\dagger}$, Utility/Unit \\
\hline
\end{tabular}


Section 6.0 - PLANT HEAT RATE

Subsection 6.3 - Recommendation for Application

Historically, heat rate has been used for two separate assessments of electrical power generating facilities:

1. as a measure of overall thermal efficiency, and

2. as a measure of the cost of electrical production.

As an index, it is proposed that the Commission use "net" heat rate, to evaluate the efficiency designed into the unit and assess the cost of generation.

The thermal efficiency of an electric generating unit is a measure of how we11 the power plant converts a fuel's available heat content (fuel energy) into useable electricity. Units that consume less fuel energy to produce the same amount of useful electric generation are thermodynamically more efficient. In other words, a unit with a higher thermal efficiency requires less fuel, of the same heat content, to produce the same amount of electric power, than does a lesser efficient unit. As can be seen from the definition of heat rate, a unit with a lower heat rate requires less, fuel, of the same heat content, to produce the same amount of electric power, than does a unit with a higher heat rate. Heat rate, therefore, is inversely proportional to the thermal efficiency of a unit, and w111 be different for different values of thermal efficiency.

The heat rate of a unit is different for operation at different power output levels, as shown in Figure 9 . The design of a unit is optimized such that the unit will have the lowest possible heat rate for its expected output level. This is done by preparing and comparing heat balance diagrams for different equipment configurations/designs for different output power levels.

The design efficiency of the proposed unit can be assessed by studying the unit heat rate. The lower the proposed heat rate, the higher is the level of efficiency of the unit. Comparison of the proposed heat rate with the historical heat rates achieved by units of similar size, fuel type, age, etc., will enable the Commission to assess the most probable efficiency level at which the new unit will produce electricity during its useful life. Instances where the proposed heat rate is higher than that which has historically been achieved, will identify for the Commission that higher efficiencies are possible: Conversely, 


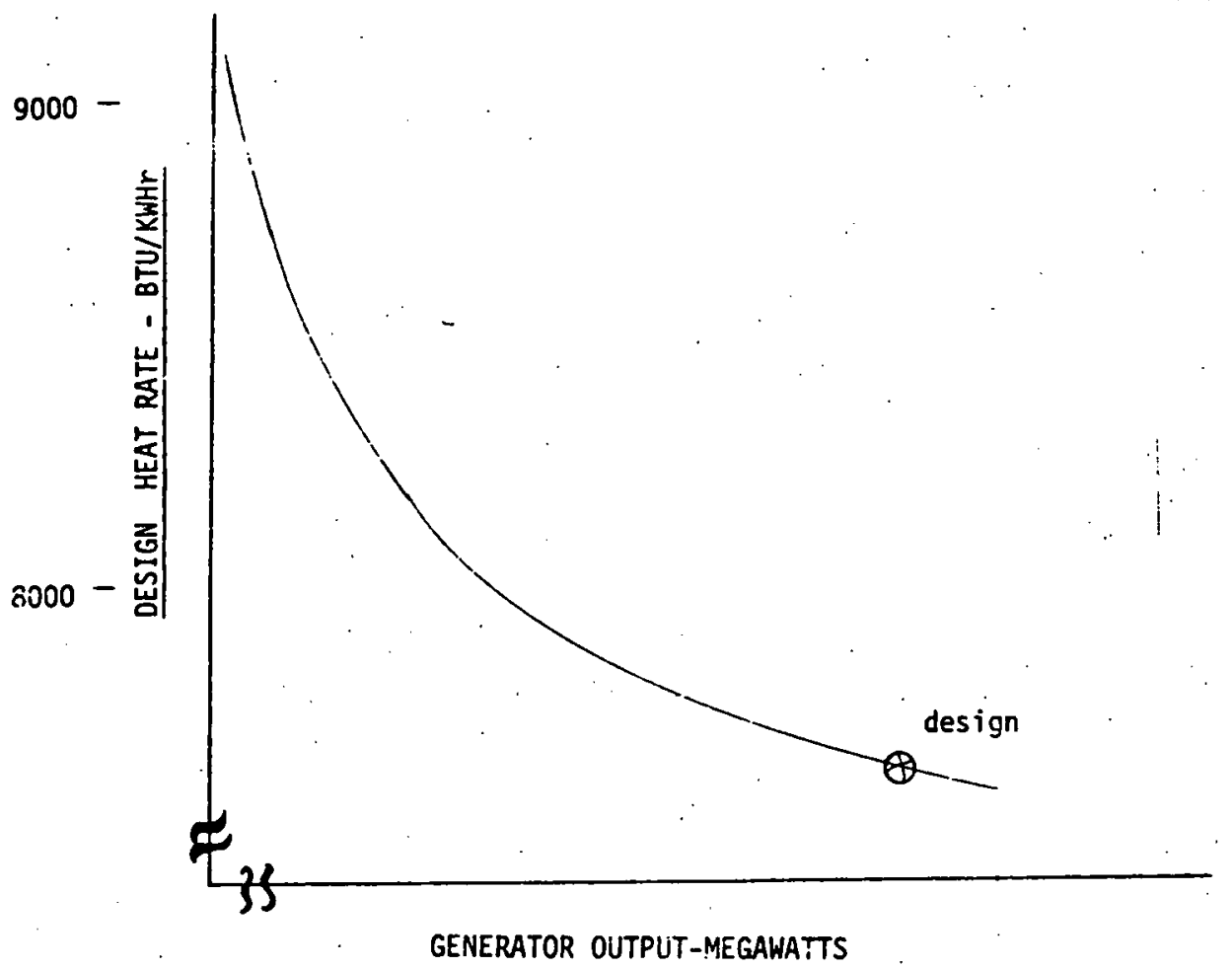

$\begin{array}{cccccc}7000 ? & 1 & 1 & 1 & 1 & 1 \\ 100 & 200 & 300 & 400 & 500 & 600\end{array}$

Figure 9: Relationship Between Heat Rate and Generator Output 
Section 6.0 - PLANT HEAT RATE

Subsection 6.3 - Recommendation for Application (Contionued

if the proposed heat rate is lower than that which has historically been achieved by similar units; the Commission will know that a higher level of efficiency, than has been historically proved possible, is being proposed. In either case, the Commission needs to investigate further the unit design to determine the utility plans to assure the lowest possible heat rate. Some of the factors the Commission has to address to ascertain the validity of the proposed value of heat rate are listed in table 9 . The factors can be lumped under three broad headings, namely, unit design, regulatory effects and institutional effects, as shown.

The Commission may also use heat rate as an indicator of cost. Both the capital cost of generation capacity and the fuel costs of generation are related to the fuel, size, age, etc., of the proposed unit. For example, large efficient base load units (coal or nuclear) will typically have a relatively large capital cost but because of a lower heat rate will have lower fuel costs per kwh generated.

The fuel cost for electrical energy is directly related to heat rate since a higher heat rate is associated with more heat energy and therefore more fuel for production of the same amount of electrical energy.

$$
\text { Fuel Cost } / /_{\text {kwh }} \text { net }=\text { Fuel Cost } / \text { BTU } x \quad \text { HR }
$$

Obviously fuel cost per BTU depends on the type of fuel used. Present day costs for oil, gas, and coal are readily available. Predictions of future costs vary widely.

To use heat rate as a measure of cost effectiveness the Commission must first agree with the need and intended application of the proposed plant. Then the basic plant and fuel type can be determined, e.g., a base loaded plant, a load following plant, or a peaking plant. Then comparisons with representative 
Table 9: Factórs Affecting Plant Heat Rate

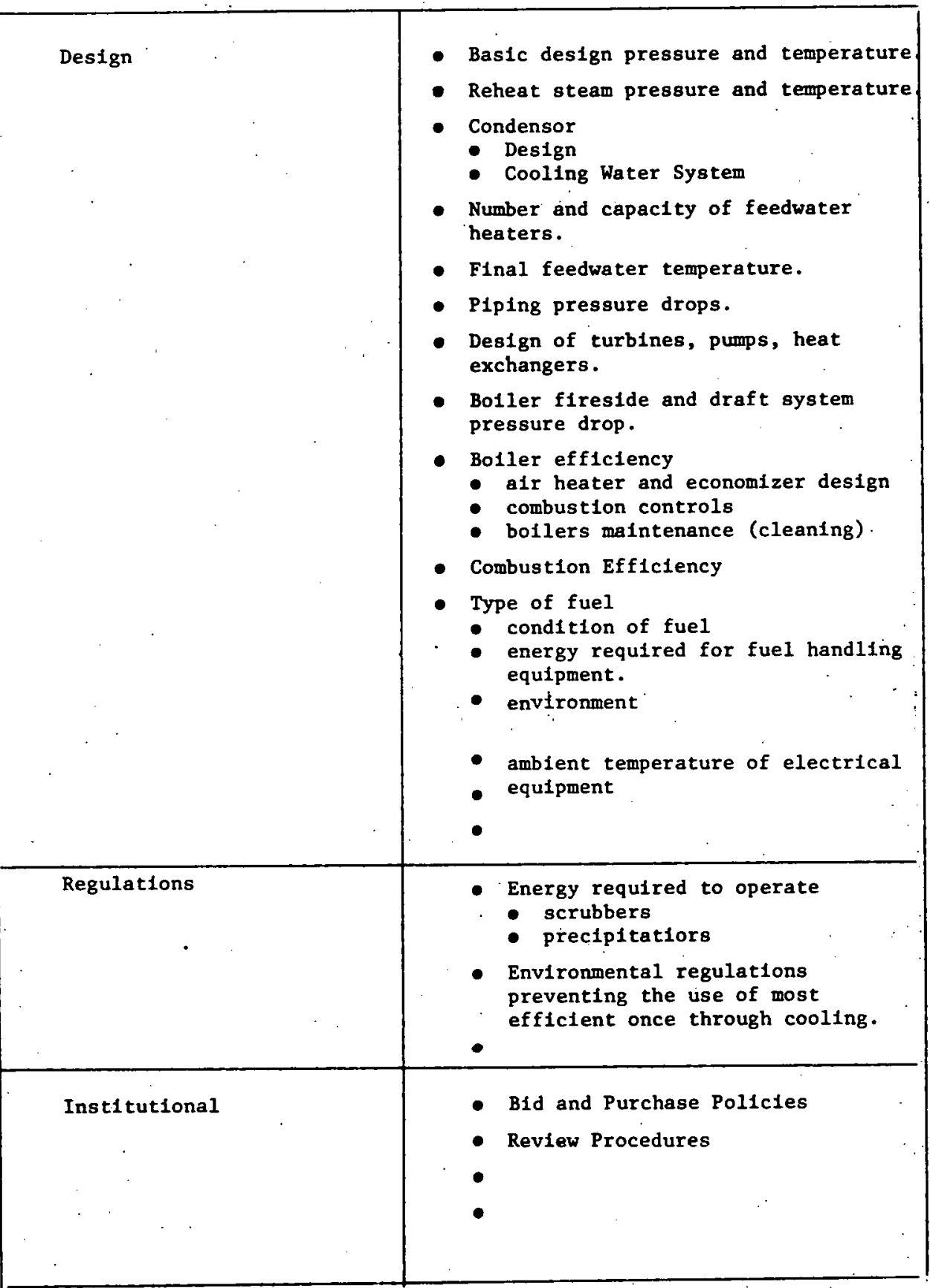


Section 6.0 - PLANT HEAT RATE

Subsection 6.3 - Recommendations for Application (Continued)

historic heat rate values will give the Commission an indication of the effic-iency of the proposed design.

The Commission must require detailed defense of the bulk fuel costs estimated by the utility for the proposed plant since the uncertainties previously discussed will bear heavily on the uncertainty in the final generation cost figures. Cost figures based upon heat rate are limited by the accuracy of the. estimates for the future price of fuel and, heat rate cannot be used directly to determine the total cost of electricity since it does not relate directly to the capital and operating and maintenance costs of generation. However, given these costs (which are probably easier to predict than the future cost of fuel), heat rate is necessary to compute the variable cost (fuel cost) portion of producting electricty. 
SECTION 7.0

COMBINATION OF R\&E INDICES 
Section 7.0 COMBINATION OF R\&E INDICES

Subsection 7.1 Capacity Factor and Operating Availability

Capacity factor is a measure of a power plants' utilization. Operating Availability is a measure of the time a power plant is available to produce same electric power. Before a power plant can be used to generate power it must be available to do so. The time period for which the plant is available is measured by the operating availability. The level of power output of the plant during the available period is measured by its capacity factor. For a plant operating at its maximum dependable capacity (MDC) for the full period it is available to do so, the capacity factor is a maximum and equals the plant operating availablity. In instances where the plant operates at levels less than its maximum dependable capacity, the capacity factor is always less than the operating availability. This is also true in instances where, while the plant may be operated at its maximum dependable capacity, it is shutdown to meet reserve requirements during the period it is available to generate same electric power. The relationship between capacity factor and operating availability can be expressed mathematically as follows :

\section{$\therefore$ Capacity factor $\leq$ Operating Availability}

Figure 10 illustrates this relationship between capacity factor and operating availability. For a plant to achieve its planned capacity factor while operating at a known average output power leve1, the minimum planned operating availability can be computed. As shown in the figure, to achieve a planned capacity factor of $80 \%$, a plant with an operating availability of $80 \%$ must operate at its Maximum Dependable Capacity. On the other hand; if the plant operates at an average output level of $0.9 \mathrm{MDC}$ it will be required to be available for $88.89 \%$ of the period. As can be seen in the figure, a boundry condition exists when a planned capacity factor of $80 \%$ is to be achieved by a plant that is available all (100\%) of the time. In such a case, the minimum average output level of the plant is required to be $0.8 \mathrm{MDC}$.

A plant may also be required to satisfy reserve requirements: For purposes of illustration, it is assumed that $5 \%$ for the time period the plant is required to 
RESERVE SHUTDOWN TIME: 0.0 HOURS

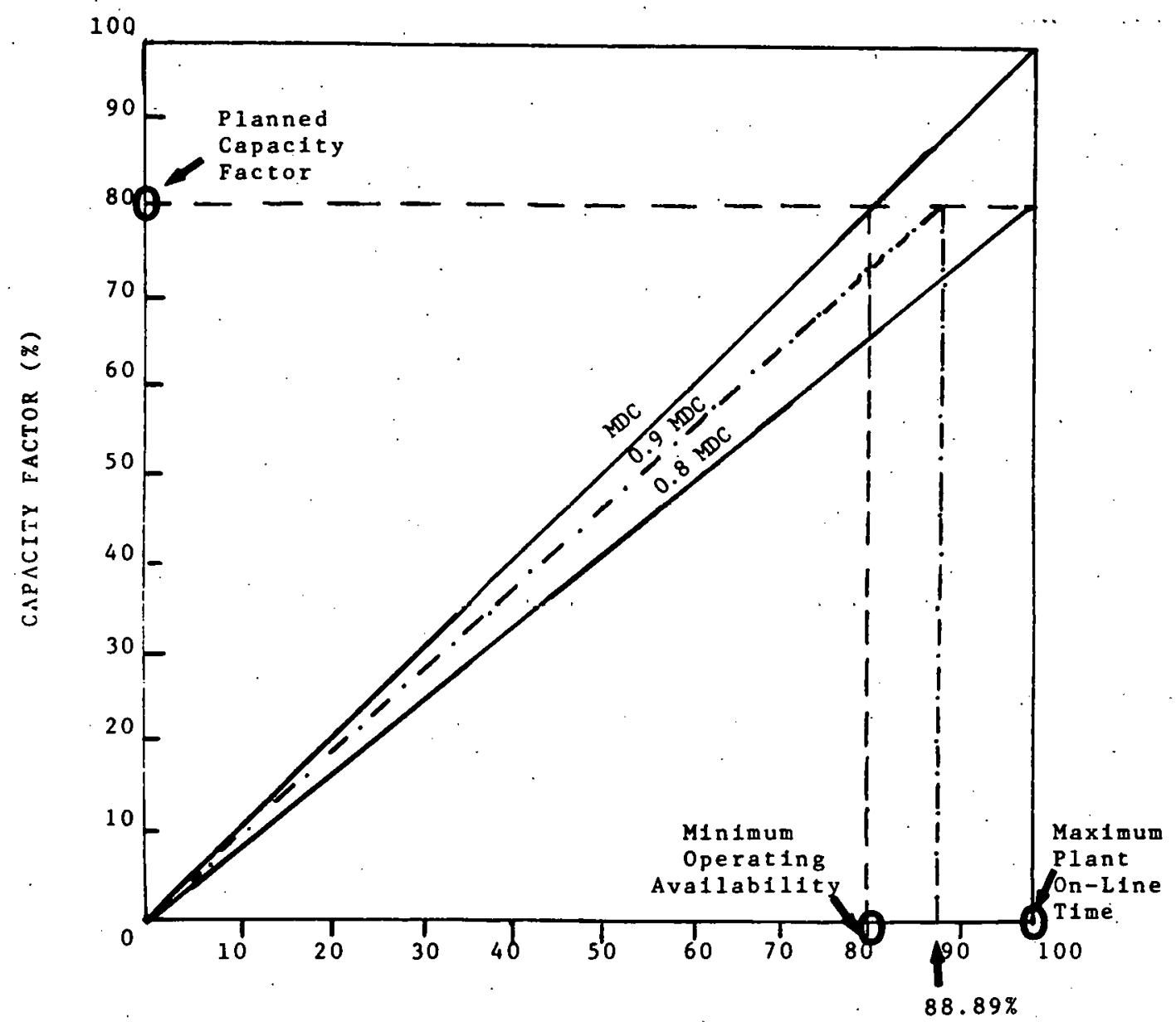

OPERATING AVAILABILITY. (\%)

Figure 10: Capacity Factor and Operating Avallability Relationships 
Section 7.0 - COMBINATION OF R\&E INDICES

Subsection 7.1 - Capacity Factor and Operating Availability (Continued)

be held in reserve and it is planned that the plant will also acheive a capacity factor of $80 \%$. Thus, as shown in figure 11 , a minimum operating availability of $85 \%$ is required ( $80 \%$ to produce electric power and $5 \%$ to meet reserve shutdown requirements) if the plant is to operate at its maximum dependable capacity. An extreme condition is when the plant is available all (100\%) of the time. $5 \%$ of the period must still be allocated to meet the required reserve shutdown hours. The plant can thus generate same level of power for $95 \%$ of the time. If the plant capacity factor is to be acheived, the average output level of the plant has to be $0.842 \mathrm{MDC}$. The plant on-line time can vary from a minimum of $80 \%$ to a maximum of $y 3 \%$. 'lhe plant operating availability varies from a minimum of $85 \%$ to a maximum of $100 \%$.

As discussed in section 4.0, operating availability provides a method for bounding the time not available for generating electric power. This time is allocated to meet the requirements of scheduled and forced plant outages. As discussed earlier, the minimum operating availability (in percent) of a power plant equals the capacity factor (in percent) if zero reserve shutdown hours are assumed. For such a case the power level at which the plant must operate, at all times; is its maximum dependable capacity (MDC). For plant operation at reduced power levels (levels less than MDC) the operating availability must be greater than the capacity factor for the plant to generate the planned amount of electrical power (i.e., $\mathrm{CF} \times \mathrm{MDC} \times \mathrm{PH}$ ). The example of the figure identifies that to achieve the planned capacity factor of $80 \%$, the power plant has to operate within two boundry conditions; (1) a minimum operating availability of $80 \%$ for a power plant operating at $\mathrm{MDC}$, and (2) the maximum operating availability of $100 \%$ for a power plant operating at 0.8 (MDC). For a minimum operating availability of $80 \%, 20 \%$ of the time period is available for full outages. For maximum operating availability of $100 \%$ no time period is available for fuil plant outages. For levels of output power between MDC and $0.8 \mathrm{MDC}$ the mintmum operating availability, and thus the period available for full outages, can be computed. 
Section 7.0 - COMBINATION OF R\&E INDICES

Subsection 7.1 - Capacity Factor and Operating Availability (Continued)

To summarize, Capacity factor and operattng avallability when specified for a power plant and based upon the same time period, thus, bound the periods of generation and non-generation (full outages) in addition to fixing the average useful energy level at which the plant needs to operate to acheive its projected capacity factor.

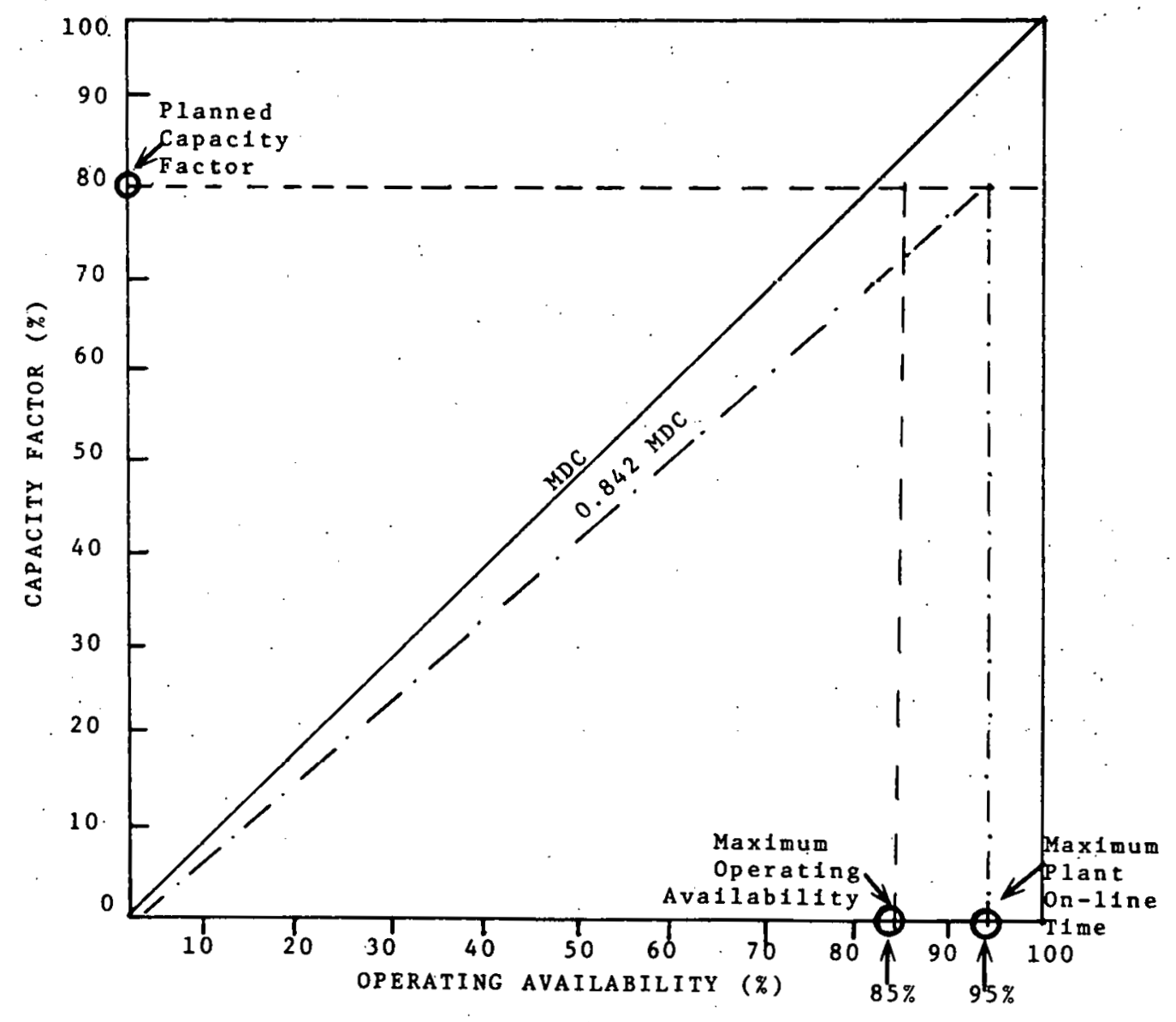

Figure 11: Capacity Factor and Operat1ng Ava1lab1l1ty Relationship Based Upon Reserve Shutdown Tine 
Section 7.0 - COMBINATION OF R\&E INDICES

Subsection 7.2 - Capacity Factor, Operating Availability and Equivalent Availability

Capacity factor is a measure of the electric power generated by a power plant. Operating availability is a measure of the time a power plant is available to produce same electric power. Equivalent availability is a measure of the time a power plant can operate at its full power level. Figure 12 graphically displays the interrelationship between capacity factor, operating availability and equivalent availability. The numerical difference between capacity factor and operating availability is due to the generation lost during reserve shutdown time and partial outage time. The numerical difference between capacity factor and equivalent availability is due to the reserve shutdown time only. The numerical difference between equivalent availability and operating availability is thus, only due to partial outages. The difference between operating availability and $100 \%$ is the full outage time.

For a plant operating at its full power level for the total period it is available to produce power, the three indices capacity factor, operating availability and equivalent availability are numerically equal. This implies that no time for reserve shutdown was taken by:; the plant and no partial outages occurred.

For a plant operating at its full power level for a period less than the period it is available to produce power, the capacity factor will be numerically less than both the equivalent availability and the operating availability. Also, if the equivalent availability and the operating availability are numerically equal, it implies that the plant was shutdown for a period of time and that no partial outages occurred during the time it generated electric power.

For a plant operating at a reduced output power level for the total period it is available to produce power, if the capacity factor is numerically equal to the equivalent availability and both capacity factor and equivalent availability are less than the operating availability,: it implies that the plant was not shutdown to meet reserve requirements. but that partial outages did occur and/or output power was.reduced to meet spinning reserve requirements. 


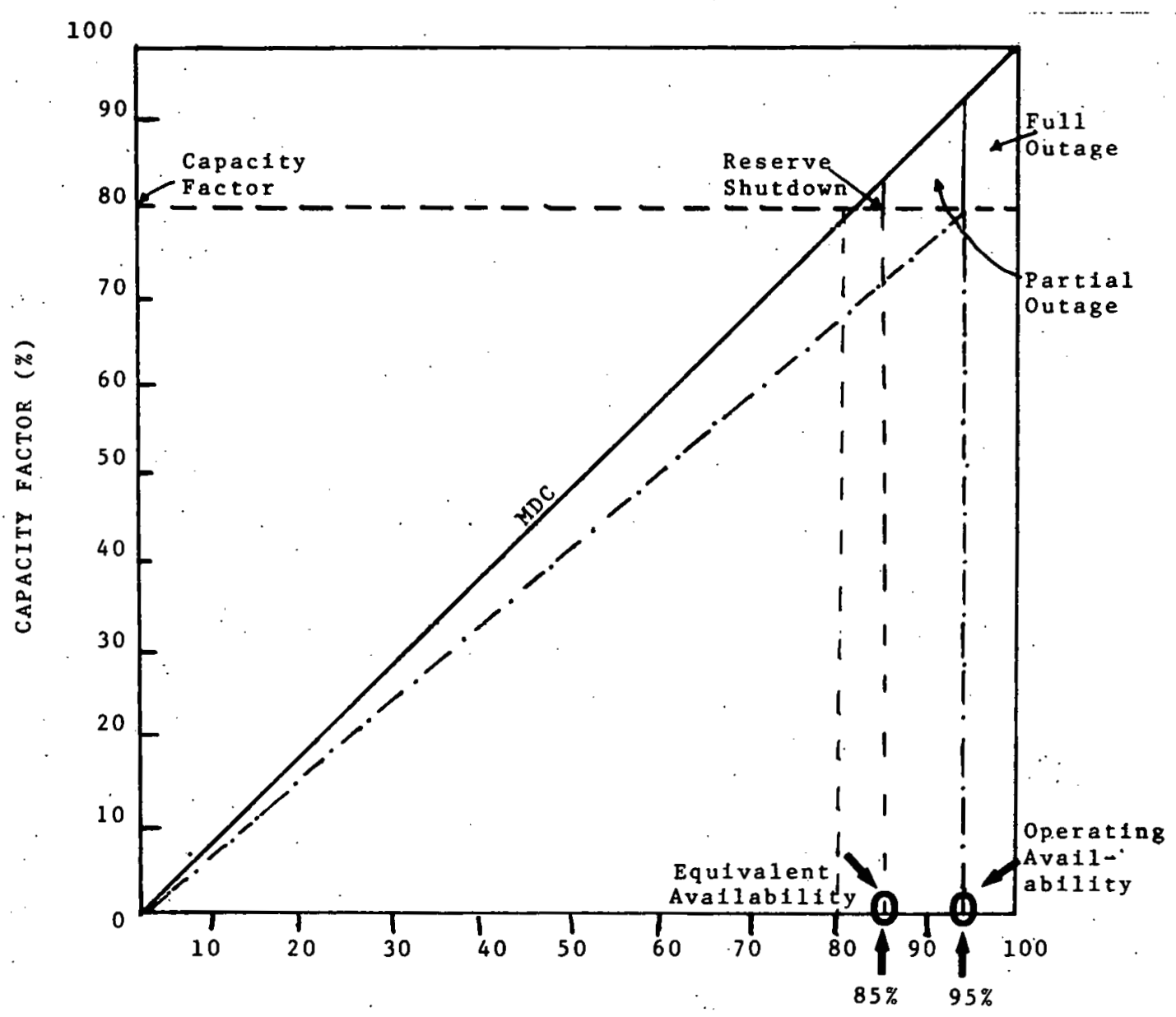

"PLANT AVAILABILITY

Figure 12: Capacity Factor, Operating Availability and Equivalent Availability 
Section 7.0 - COMBINATION OF R\&E INDICES

Subsection 7.2 - Capacity Factor, Operating Availability and Equivalent Availability ( Continued)

For a plant operating at a reduced output power level for a period less than the period it is available to produce power, the capacity factor is numerically less than the equivalent availability which is numerically less than the operating availability. In such an instance, the plant must have been shutdown to meet reserve requirements and it must also have operated at reduced power levels due to outages or to meet spinning reserve requirements. 